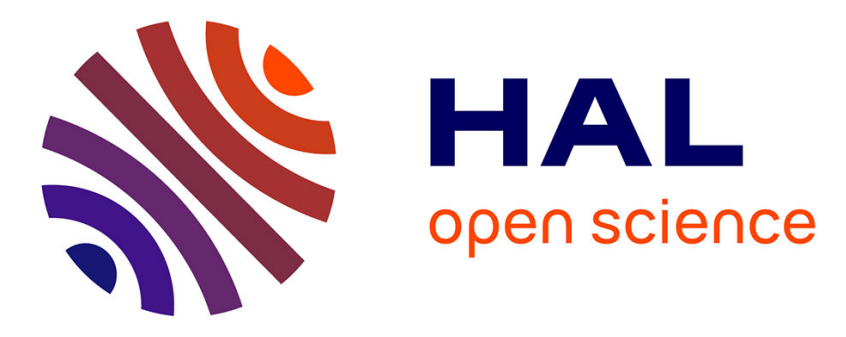

\title{
Multiscale modeling of upper mantle plasticity: From single-crystal rheology to multiphase aggregate deformation
}

Paul Raterron, Fabrice Detrez, Olivier Castelnau, Caroline Bollinger, Patrick Cordier, Sebastien Merkel

\section{To cite this version:}

Paul Raterron, Fabrice Detrez, Olivier Castelnau, Caroline Bollinger, Patrick Cordier, et al.. Multiscale modeling of upper mantle plasticity: From single-crystal rheology to multiphase aggregate deformation. Physics of the Earth and Planetary Interiors, 2014, 228, pp.232-243. 10.1016/j.pepi.2013.11.012 . hal-00980640

\section{HAL Id: hal-00980640 https://hal.science/hal-00980640}

Submitted on 13 May 2014

HAL is a multi-disciplinary open access archive for the deposit and dissemination of scientific research documents, whether they are published or not. The documents may come from teaching and research institutions in France or abroad, or from public or private research centers.
L'archive ouverte pluridisciplinaire HAL, est destinée au dépôt et à la diffusion de documents scientifiques de niveau recherche, publiés ou non, émanant des établissements d'enseignement et de recherche français ou étrangers, des laboratoires publics ou privés. 


\title{
Multiscale modeling of upper mantle plasticity: From single-crystal rheology to multiphase aggregate deformation
}

\author{
Paul Raterron ${ }^{\mathrm{a}, *}$, Fabrice Detrez $^{\mathrm{b}, 1}$, Olivier Castelnau ${ }^{\mathrm{b}}$, Caroline Bollinger ${ }^{\mathrm{a}}$, Patrick Cordier ${ }^{\mathrm{a}}$, \\ Sébastien Merkel $^{\text {a }}$ \\ a Unité Matériaux Et Transformations (UMET), CNRS, Université Lille 1, F-59655 Villeneuve d'Ascq, France \\ ${ }^{\mathrm{b}}$ Procédés et Ingénierie en Mécanique et Matériaux (PIMM), CNRS, Arts et Métiers ParisTech, 151, boulevard de l'Hôpital, F-75013 Paris, France
}

Keywords:

Upper mantle

Plasticity

Olivine

Diopside

Dislocation

Multiphase aggregate

Viscoplastic modeling

\begin{abstract}
A B S T R A C T
We report a first application of an improved second-order (SO) viscoplastic self-consistent model for multiphase aggregates, applied to an olivine + diopside aggregate as analogue for a dry upper mantle peridotite deformed at $10^{-15} \mathrm{~s}^{-1}$ shear strain rate along a 20-Ma ocean geotherm. Beside known dislocation slip systems, this SO-model version accounts for an isotropic relaxation mechanism representing 'diffusionrelated' creep mechanisms in olivine. Slip-system critical resolved shear stress (CRSS) are evaluated in both phases - as functions of $P, T$, oxygen fugacity $\left(\mathrm{fO}_{2}\right)$ and strain rate - from previously reported experimental data obtained on single crystals and first-principle calculations coupled with the Peierls-Nabarro model for crystal plasticity; and the isotropic-mechanism dependence on $T$ and $P$ matches that of Si selfdiffusion in olivine, while its relative activity is constrained by reported data. The model reproduces well the olivine and diopside lattice preferred orientations (LPO) produced experimentally and observed in naturally deformed rocks, as well as observed sensitivities of multiphase aggregate strength to the volume fraction of the hard phase (here diopside). It shows a significant weakening of olivine LPO with increasing depth, which results from the combined effects of the $P$-induced [100]/[001] dislocation-slip transition and the increasing activity with $T$ of 'diffusion-related' creep. This work thus provides a first quantification of the respective effects of [100]/[001] slip transition and diffusion creep on the olivine LPO weakening inducing the seismic anisotropy attenuation observed in the upper mantle.
\end{abstract}

\section{Introduction}

Thermal convection in Earth's upper mantle is constrained by the high temperature $(T)$ and high pressure $(P)$ plastic properties of peridotite, a rock consisting mostly of olivine, pyroxenes and garnet which respective volume fractions are about 60\%, 30\% and $10 \%$ at depths <200 km (e.g., Frost, 2008). Olivine and pyroxenes present marked elastic and plastic anisotropies (e.g., Mainprice et al., 2000; Hansen et al., 2013) which are responsible for significant stress and strain-rate heterogeneities within the deforming aggregate, at the grain or sub-grain scales. Plastic strain translates into lattice preferred orientations (LPO) in rocks deformed by dislocation creep, which in turn induce seismic anisotropies (e.g., Ohuchi et al., 2011). Since the theory of plate tectonics was established in the early 1960s, quantifying upper-mantle mineral and aggregate plastic properties has become a major quest for

\footnotetext{
* Corresponding author. Tel.: +33 (0) 32022 1132; fax: +33 (0) 320226591

E-mail address: Paul.Raterron@univ-lille1.fr (P. Raterron).

1 Present address: Laboratoire de Modélisation et Simulation Multi Echelle (MSME), CNRS, Université Paris-Est, Boulevard Descartes, F-77454 Marne-la-Vallée Cedex 2, France.
}

experimental mineralogy, with direct implications in seismology, geodynamics and tectonics. The investigation of mantle materials deformation raises, however, serious difficulties which include understanding the complex mechanisms involved in multiphase aggregate plasticity at high temperature, quantifying the effects of extreme pressures and temperatures on these mechanisms, and addressing stress and strain scaling issues between laboratory experiments and natural deformations. The 'standard' approach (e.g., Hansen et al., 2013) consists in carrying out deformation experiments on mantle aggregates, usually sintered from individual minerals mixed in various proportions, and analyzing the data using empirical rheological laws such as the classical high-temperature power law:

$\dot{\varepsilon}=A \sigma^{n} f \mathrm{O}_{2}^{m} \exp -\frac{E^{*}+P V^{*}}{R T}$

where $\dot{\varepsilon}$ is the strain rate, $A$ is a pre-exponential factor, $\sigma=\sigma_{1}-\sigma_{3}$ is the differential stress with $\sigma_{1}$ the principal stress, $\mathrm{fO}_{2}$ is the oxygen fugacity, $n$ and $m$ are constants, $E^{*}$ and $V^{*}$ are respectively the activation energy and volume, and $R$ is the gas constant. Eq. (1) can accommodate other terms quantifying the sensitivity to the aggregate 
grain-size $(d)$, the pyroxenes activity $\left(a_{O P x}\right)$, the hydroxyl concentration in minerals $\left(C_{\mathrm{OH}}\right)$, etc. Recent developments in high- $P$ deformation devices installed at synchrotron facilities (a review in Raterron and Merkel, 2009; see also Liebermann, 2011) allow carrying out 'standard' deformation experiments at pressure representative of the upper mantle (e.g., Durham et al., 2009; Bollinger et al., 2013). The 'standard' approach provides a single empirical law for the aggregate plasticity, which can be easily implemented into geodynamical modeling. It assumes, however, that the law parameters $\left(A, n, m, E^{*}\right.$ and $V^{*}$ in Eq. (1)) are constant over relevant $P$ and $T$ ranges and can extrapolate to natural stresses, i.e. that there is no significant differences between the mechanisms responsible for deformations in the laboratory and along mantle geotherms. This assumption in not verified for mantle aggregates deforming in the dislocation creep regime, since olivine and clinopyroxenes (CPx) exhibit marked transitions induced by pressure in their dominant dislocation slip systems (Couvy et al., 2004; Raterron et al., 2007, 2009, 2011, 2012; Amiguet et al., 2009; Jung et al., 2009; Ohuchi et al., 2011;). Besides, olivine and pyroxenes slip systems exhibit different stress sensitivities (e.g., Bai et al., 1991; Raterron and Jaoul, 1991) which cannot be accounted for by a single $n$ exponent in the rheological law. These limitations question whether single rheological laws such as Eq. (1) extrapolate to natural deformation at mantle pressure and stress conditions.

Another approach to investigate upper mantle plasticity consists in integrating known mineral deformation mechanisms (i.e., dislocation glide, grain boundary sliding, etc.) into full-field or mean-field numerical models for mantle aggregate (e.g., Tommasi et al., 2000; Kaminski et al., 2004; Castelnau et al., 2008a, 2009; for dislocation climb see Lebensohn et al., 2010). In full-field models (e.g., finite-element models), the aggregate grains (size and shape) are input of the modeling, while in mean-field models grains orientations are implemented in the model and treated as inclusions into an homogeneous matrix. Generally speaking, five independent slip systems are required for a given grain to undergo any arbitrary amount of isochoric plastic strain (the so-called von Mises criterion). But four independent systems are in fact sufficient to ensure compatibility of strain throughout a polycrystalline aggregate with grains accommodating different amounts of strain (Hutchinson, 1977). The issue with olivine is that there is a lack independent slip systems, since less than four independent systems are available. Without any additional deformation mechanism, plastic deformation of an olivine polycrystal cannot occur. The usual way to address this issue is to implement fictitious dislocation slip systems, (e.g. Wenk and Tomé, 1999; Tommasi et al., 2000). The strength of each system is also often arbitrarily set, in order to reproduce the LPO observed in deformed rocks, which weakens the conclusions drawn from the modeling. To overcome this limitation, Castelnau et al. (2010) report a better constrained micromechanical model, adapted to olivine aggregates, within which the critical resolved shear stresses (CRSS) of the active slip systems are quantified from deformation experiments carried out on single crystals (e.g., Bai et al., 1991; Raterron et al., 2009), and from firstprinciple calculations and theoretical modeling of crystal plasticity (e.g., Durinck et al., 2007). This model benefits from improvements in the theoretical formulation of mean-field homogenization methods, the so-called second-order (SO) method (Ponte Castañeda, 2002) which provides a correct estimate (qualitative and quantitative) for the strength of mechanical interactions between grains as the aggregate deforms. In particular, this model provides very accurate results for highly anisotropic non-linear materials such as silicates (Lebensohn et al., 2007; Castelnau et al., 2008a, 2008b), e.g. when compared to full-field 'reference' numerical solutions. Castelnau et al. (2010) model accounts for the effects of $P, T$, $\mathrm{fO}_{2}$ and $\sigma$ on individual deformation mechanisms by adjusting slipsystem CRSS when calculating the aggregate viscous responses and resulting LPO to a given deformation. Although the microstructure (grain size, nature of grain boundaries, local grain arrangements) is not explicitly described in the model, interactions between different crystallographic orientations are taken into account through the self-consistent homogenization scheme. Previous applications of this mean-field scheme, however, does not accommodate different minerals, neither deformation mechanisms involving ionic diffusion such as Coble and/or Nabarro-Herring diffusion creep, grain-boundary migration and sliding, etc. These mechanisms are critical in upper mantle rocks, because olivine does not have sufficient independent slip systems, and therefore the peridotite deformation necessarily involves additional deformation mechanisms probably related to short range or long range diffusion and, hence, labeled as 'diffusion-related' mechanisms.

In a forthcoming article, Detrez et al. (in preparation) detail an improvement of the SO model, which is the implementation of an isotropic linear (i.e., linear viscosity) deformation mechanism which strength can be adjusted with respect to other deformation mechanisms. The isotropic mechanism represents the above-mentioned 'diffusion-related' mechanisms which were not accounted for in previous modeling; thus ensures strain compatibility throughout the aggregate without resorting to fictitious dislocation slip systems. We report here an application of the method to the case of a multiphase (i.e. multi-mineral) aggregate, each mineral with its own set of slip systems with adjustable strengths and stress sensitivities. For this first application, we chose CPx as second phase because it exhibits the highest elastic anisotropy among mantle minerals (Mainprice et al. 2000), i.e. despite its small volume fraction in the upper mantle rocks ( 10\%) CPx LPO may have significant effect on deformed rocks seismic anisotropy. The implemented CPx is here diopside because its single-crystal plasticity has been experimentally and theoretically documented over large $P$ and $T$ ranges (details below). The aim of this study is: (i) to investigate the effect of a hard phase on peridotite plasticity, (ii) to evaluate the effect of $P$-induced slip-system transitions on the aggregate LPO, and (iii) to quantify the contribution of dislocation glide (versus a temperature dependent isotropic component) on its plasticity and resulting LPO.

\section{Experimental input and computational details}

The inputs of the present model are olivine and diopside crystallographic data, and for each mineral a list of the active slip systems with their geometry together with parameters specifying stress sensitivities and relative strengths at given $P, T, f \mathrm{O}_{2}$ and $\dot{\varepsilon}$ conditions, i.e., for each slip system: Eq. (1) stress exponent $n$ and the critical resolved shear stress (CRSS) at given conditions. The CRSS $\left(\tau_{0}\right)$ of a given slip system is the shear stress resolved in the glide plane in the direction of slip (i.e. along the Burgers vector direction) promoting a plastic shear rate $\dot{\gamma}_{0}$ due to dislocation motions. To establish the list of the required parameters, we use primarily the experimental data obtained from single-crystal deformation, and secondarily the data obtained from first principle calculations and theoretical modeling of crystal plasticity.

While deforming a single crystal in axisymmetric compression, its crystallographic orientation imposes the resolved shear stress $(\tau)$ for each slip system. $\tau$ is quantified by the Schmid factor $S=\tau / \sigma$ which is maximum $(S=1 / 2)$ when both the Burgers vector and the glide-plane normal are oriented at $45^{\circ}$ angles from the principal stress $\left(\sigma_{1}\right)$ direction. If $S=0$, then $\tau=0$ and the slip system cannot be activated; intermediate geometries result into intermediate resolved shear stresses. By choosing appropriately the crystal orientation, one can investigate specific slip-system activities. Strain rates measured on oriented crystals can, thus, be used as proxies for comparing slip-system activities at given $P, T, \mathrm{fO}_{2}$ 
and $\tau$ conditions. Conversely, slip systems resolved shear stress obtained at given $P, T, f \mathrm{O}_{2}$, and $\dot{\varepsilon}$ conditions - are used here to evaluate slip-system CRSS at these conditions.

Because of geometrical limitations, dislocation slip system activity cannot always be investigated individually during axisymmetric deformation of oriented crystals. Computational studies, based on first principle calculation of generalized stacking fault (GSF) energies, coupled with the classic Peierls-Nabarro model for crystal plasticity, provide then information on slip-system Peierls stress $\left(\tau_{\mathrm{p}}\right)$ and dislocation core structures (for olivine: Durinck et al., 2007; for diopside: Metsue et al., 2010). This approach has been tested and proven reliable on a number of materials (e.g., for the perovskite structure: Ferré et al., 2008, and Carrez et al., 2010). At given $P$, the Peierls stress of a given dislocation slip can be viewed as its CRSS at $0 \mathrm{~K}$. It is strongly related to the dislocation core structure, which in oxides and silicate can be quite large and extended in space (for forsterite: Carrez et al., 2008). Calculated slip-system relative Peierls stresses can thus be used as proxies for slip-system relative CRSS. They are used here to estimate the CRSS of dislocation slip systems which cannot be geometrically isolated from those of other slip systems obtained from single-crystal deformation experiments. Using this first-order approximation, the effect of temperature on the relative strengths of the compared slip systems is not accounted for, i.e., it supposes that the compared slip systems have the same thermal activation. Dislocation glide thermal activation depends on the energy barrier between two adjacent Peierls valleys and the geometry of dislocation double kinks, which in turn depend on dislocation core structures and glide plane characteristics. It is in general strongly slip-system dependent. In order to limit the errors induces by assimilating Peierls-stress ratios to CRSS ratios, we always compare the Peierls stresses of slip systems sharing the same Burgers vector.

\subsection{Olivine slip-system CRSS}

The rheology of $\mathrm{Mg}_{1.8} \mathrm{Fe}_{0.2} \mathrm{SiO}_{4}$ olivine single crystals has been extensively studied experimentally (Phakey et al., 1972; Kohlstedt and Goetze, 1974; Durham and Goetze, 1977; Poumellec and Jaoul, 1984; Mackwell et al., 1985; Ricoult and Kohlstedt, 1985; Bai et al., 1991; Bai and Kohlstedt, 1992a, 1992b; Demouchy et al., 2009; Raterron et al., 2009, 2012; Girard et al., 2013). In olivine (Pbnm space group; $a \sim 4.76 \AA, b \sim 10.23 \AA, c \sim 5.99 \AA$ ), only [1 00] and [001] Burgers vectors are activated at high temperature, respectively in the glide planes (010), (001) or (021), and (100), (010)

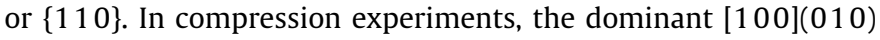
or [001](010) slip systems can be individually investigated, and [100](001) and [001](100) slip systems can be activated simultaneously. These later systems have also been activated individually in simple shear deformation experiments (Tielke et al., 2012). The other olivine slip systems considered here are [100](021) and $[001]\{110\}$ systems; they cannot be activated individually in compression experiments and were never studied in simple-shear experiments. Their respective CRSS are thus evaluated from computational studies by comparison with those of the well characterized [100](010) and [001](010) systems, respectively.

We use the data reported by Bai et al. (1991), Raterron et al. (2009) and (2012) for dry San Carlos olivine crystals in equilibrium with pyroxenes $\left(a_{\mathrm{OPx}}=1\right)$, deformed in the crystallographic orientations $[110]_{\mathrm{c}},[011]_{\mathrm{c}}$, and $[101]_{\mathrm{c}}$; here the $\mathrm{c}$ index indicates the pseudo-cubic notation, i.e., for instance $[110]_{c}$ direction is at $45^{\circ}$ angle from both [100] and [0 10] directions. These orientations allow activating respectively $[100](010)$ slip system alone, $[001](010)$ system alone, and [100](001) and [001](100) activated together, all systems with $S=1 / 2$. In the case of $[110]_{\mathrm{c}}$ or $[011]_{\mathrm{c}}$ crystals, the obtained $\tau$ gives directly the values for respectively $[100](010)$ or $[001](010)$ system CRSS $\left(\tau_{0}\right)$. In the case of
[101] c orientation, since [001](100) is weaker than [100](001) (Tielke et al., 2012), we attribute arbitrarily $2 / 3$ of the crystal strain (and strain rate) to the former system and 1/3 to the latter system, i.e. we assume that [001](100) is two times weaker in terms of strain rate than [100](001). The corresponding CRSS are obtained by applying a correction factor to the measured $\tau$ - respectively (3/ $2)^{1 / 3.5}$ and $(3 / 1)^{1 / 3.5}$ - thus accounting for olivine strain-rate sensitivity to stress assuming $n=3.5$ in Eq. (1). This stress exponent has been quantified from deformation experiments carried out at low pressure on olivine single crystals as well as aggregates (e.g., Bai and Kohlstedt, 1992a; a review in Hirth and Kohlstedt (2003)). Whether this stress exponent applies to olivine rheology at high pressure is still unclear, since the large uncertainty affecting stress measurements at high pressure (Raterron and Merkel, 2009) prevents settling this point. In this analysis, we thus lean on low- $P$ deformation experiments and assume $n=3.5$, a value well accepted by the community. For the [100](021) and [001]\{110\} slip systems, we used the results of Durinck et al. (2007) who calculated olivine slip-system Peierls stress $\left(\tau_{\mathrm{p}}\right)$ at 0 and $10 \mathrm{GPa}$ pressure, from GFS energies and theoretical considerations. It appears that the $\tau_{\mathrm{p}}$ for [100] edge dislocations in (021) is about twice that in $(010)$. For [100] screw dislocation, an inverse $\tau_{\mathrm{p}}$ ratio is obtained at $0 \mathrm{GPa}$, i.e. $\tau_{\mathrm{p}}$ in $(021)$ plane is about half that in (010); at $10 \mathrm{GPa}$, this ratio becomes $\sim 1 / 5$. Roughly averaging the above $\tau_{\mathrm{p}}$ for both [100] edge and screw dislocations, the Peierls stress for [100](010) and [100](021) systems appears fairly comparable in most conditions. Consequently, in the present model we impose to [100](021) the same CRSS than for [100](010). To evaluate the CRSS of [001] $\{110\}$ system, however, we use only the theoretical $\tau_{\mathrm{p}}$ ratios reported for [001] edge dislocations; this is because the mobility of [001] screw dislocation at high pressure is significantly enhanced by cross slip (e.g., Raterron et al., 2009). In other words, unlike [100] screw dislocations, [001] screw dislocations easily change plane, i.e. they are not representative of a single slip system. The reported Peierls stress at 0 and $10 \mathrm{GPa}$ for [001] edge dislocation glide in (110) plane is $\sim 3$ times that for glide in $(010)$ (Durinck et al., 2007); we thus set in the model the CRSS for $[001]\{110\}$ systems 3 times larger than that measured experimentally for [001](010).

The CRSS for olivine slip systems calculated along a 20-Ma ocean geotherm at shear strain rate $\dot{\gamma}=\frac{1}{2} \dot{\varepsilon}=10^{-15} \mathrm{~s}^{-1}$, from either experimental flow laws or the above theoretical considerations, are reported in Table 1 and plotted on Fig. 1a. Fe-bearing olivine plasticity is sensitive to $\mathrm{fO}_{2}$ (Bai et al., 1991). We set $f_{2}$ two order of magnitude below that of the fayalite-magnetite-quartz buffer (FMQ, see Frost, 1991), which is a reasonable assumption for upper mantle peridotites (Frost and McCammon, 2008). Changing $\mathrm{fO}_{2}$ over a few orders of magnitude would not significantly affect our results because olivine crystal plasticity is weakly sensitive to $\mathrm{fO}_{2}$ $(0.02 \leqslant m \leqslant 0.36$ in Eq. 1$)$.

\subsection{Diopside slip-system CRSS}

The plasticity of CPx single crystals has been the topic of a number of experimental studies (Avé Lallemant, 1978; Kollé and Blacic, 1982, 1983; Ingrin et al., 1991, 1992; Raterron and Jaoul, 1991; Jaoul and Raterron, 1994; Raterron et al., 1994; Amiguet et al., 2009, 2010). In $\mathrm{Ca}(\mathrm{Mg}, \mathrm{Fe}) \mathrm{Si}_{2} \mathrm{O}_{6}$ diopside (C2/c space group; $a \sim 9.75 \AA, b \sim 8.90 \AA, c \sim 5.3 \AA$; $\left.\beta \sim 105.8^{\circ}\right)$, as in all pyroxenes, dislocation glide in the (001) plane is forbidden because of the chains of tetrahedral $\mathrm{SiO}_{4}$ align along [001] axis (called "I-beam" by Cameron and Papike, 1981). Consequently, the potential glide planes are all in zone with [001] axis; we consider here (100), (010) and $\{110\}$ planes. At high temperature, the observed slip systems in diopside are $1 / 2<110>\{110\},[100](010),[010](100)$ 
Table 1

Slip-system CRSS along a typical 20-Ma ocean geotherm at shear strain rate $\dot{\gamma}=10^{-15} \mathrm{~s}^{-1}$.

\begin{tabular}{|c|c|c|c|c|c|c|c|c|c|c|c|c|c|}
\hline \multirow{2}{*}{$\begin{array}{l}\text { Depth } \\
(\mathrm{km})\end{array}$} & \multirow{2}{*}{$\begin{array}{l}P \\
(\mathrm{GPa})\end{array}$} & \multirow{2}{*}{$T(\mathrm{~K})$} & \multirow{2}{*}{$\begin{array}{l}\mathrm{fO}_{2} \times 10^{9} \\
(\mathrm{~atm})\end{array}$} & \multicolumn{6}{|c|}{ Olivine (MPa) } & \multicolumn{4}{|c|}{ Diopside (MPa) } \\
\hline & & & & {$[100](010)$} & {$[001](010)$} & {$[001](001)$} & {$[100](001)$} & {$[100](021)$} & {$[001]\{110\}$} & $<110>\{110\}$ & {$[010](100)$} & {$[001](110)$} & {$[001](100)$} \\
\hline 60 & 1.97 & 1444 & 0.02 & 0.50 & 0.90 & 0.55 & 0.67 & 0.50 & 2.69 & 4.09 & 20.2 & 5.98 & 47.9 \\
\hline 75 & 2.47 & 1538 & 0.27 & 0.24 & 0.40 & 0.23 & 0.28 & 0.24 & 1.20 & 3.10 & 16.8 & 4.17 & 33.3 \\
\hline 90 & 2.96 & 1582 & 0.75 & 0.16 & 0.29 & 0.17 & 0.21 & 0.16 & 0.87 & 2.91 & 16.4 & 3.72 & 29.7 \\
\hline 105 & 3.45 & 1596 & 1.04 & 0.15 & 0.27 & 0.17 & 0.21 & 0.15 & 0.80 & 3.05 & 17.3 & 3.76 & 30.1 \\
\hline 120 & 3.95 & 1604 & 1.25 & 0.16 & 0.26 & 0.18 & 0.22 & 0.16 & 0.78 & 3.27 & 18.6 & 3.90 & 31.2 \\
\hline 135 & 4.44 & 1612 & 1.49 & 0.16 & 0.25 & 0.19 & 0.23 & 0.16 & 0.75 & 3.50 & 20.0 & 4.04 & 32.3 \\
\hline 150 & 4.94 & 1620 & 1.78 & 0.17 & 0.24 & 0.20 & 0.24 & 0.17 & 0.73 & 3.74 & 21.5 & 4.19 & 33.5 \\
\hline 165 & 5.43 & 1628 & 2.13 & 0.17 & 0.24 & 0.21 & 0.25 & 0.17 & 0.71 & 3.99 & 23.0 & 4.34 & 34.7 \\
\hline 180 & 5.92 & 1636 & 2.53 & 0.18 & 0.23 & 0.22 & 0.26 & 0.18 & 0.69 & 4.26 & 24.7 & 4.49 & 36.0 \\
\hline 195 & 6.42 & 1644 & 3.01 & 0.19 & 0.22 & 0.23 & 0.28 & 0.19 & 0.67 & 4.55 & 26.4 & 4.65 & 37.2 \\
\hline 210 & 6.91 & 1652 & 3.57 & 0.19 & 0.22 & 0.24 & 0.29 & 0.19 & 0.65 & 4.85 & 28.3 & 4.82 & 38.5 \\
\hline 225 & 7.40 & 1660 & 4.22 & 0.20 & 0.21 & 0.25 & 0.31 & 0.20 & 0.63 & 5.17 & 30.3 & 4.98 & 39.9 \\
\hline 240 & 7.90 & 1668 & 4.99 & 0.21 & 0.20 & 0.26 & 0.32 & 0.21 & 0.61 & 5.51 & 32.4 & 5.15 & 41.2 \\
\hline 255 & 8.39 & 1676 & 5.90 & 0.23 & 0.20 & 0.28 & 0.34 & 0.23 & 0.59 & 5.86 & 34.6 & 5.33 & 42.6 \\
\hline 270 & 8.88 & 1684 & 6.95 & 0.24 & 0.19 & 0.29 & 0.36 & 0.24 & 0.58 & 6.23 & 36.9 & 5.51 & 44.1 \\
\hline 285 & 9.38 & 1692 & 8.17 & 0.25 & 0.19 & 0.31 & 0.38 & 0.25 & 0.56 & 6.63 & 39.4 & 5.69 & 45.5 \\
\hline 300 & 9.87 & 1701 & 9.60 & 0.27 & 0.18 & 0.32 & 0.39 & 0.27 & 0.54 & 7.04 & 42.0 & 5.88 & 47.0 \\
\hline 315 & 10.4 & 1709 & 11.3 & 0.29 & 0.18 & 0.34 & 0.42 & 0.29 & 0.53 & 7.48 & 44.7 & 6.07 & 48.5 \\
\hline 330 & 10.9 & 1717 & 13.2 & 0.30 & 0.17 & 0.36 & 0.44 & 0.30 & 0.51 & 7.93 & 47.6 & 6.26 & 50.1 \\
\hline 345 & 11.4 & 1725 & 15.4 & 0.32 & 0.17 & 0.38 & 0.46 & 0.32 & 0.50 & 8.42 & 50.7 & 6.47 & 51.7 \\
\hline 360 & 11.8 & 1733 & 18.0 & 0.35 & 0.16 & 0.40 & 0.49 & 0.35 & 0.49 & 8.92 & 53.9 & 6.67 & 53.4 \\
\hline 375 & 12.3 & 1741 & 21.0 & 0.37 & 0.16 & 0.42 & 0.51 & 0.37 & 0.47 & 9.45 & 57.3 & 6.88 & 55.0 \\
\hline 390 & 12.8 & 1749 & 24.5 & 0.40 & 0.15 & 0.44 & 0.54 & 0.40 & 0.46 & 10.0 & 60.9 & 7.09 & 56.8 \\
\hline 405 & 13.3 & 1757 & 28.5 & 0.42 & 0.15 & 0.46 & 0.56 & 0.42 & 0.45 & 10.6 & 64.7 & 7.31 & 58.5 \\
\hline
\end{tabular}

and $[001]\{110\}$, with marginal contributions of $[001](100)$ and $[100](010)$ systems. No evidence of the potential [001](010) system is found in run products from high- $P$ deformation experiments. In axial compression, the duplex $1 / 2<1 \overline{1} 0>\{110\}$ slip systems can be activated together $(S \sim 1 / 2)$ without contribution from other systems. Similarly [100](010) and [010](100) can be activated simultaneously in compression $(S \sim 1 / 2)$ with no significant contribution of the other known systems. Activation of [001]\{110\} with $S \sim 1 / 2$ is also possible in compression, but in this geometry $[010](100),[100](010)$ and $[001](100)$ systems are also significantly sheared $(0.20 \leqslant S \leqslant 0.36)$; yet the very low activities of the latter systems compared to that of $[001]\{110\}$ can be omitted in a first-order approximation.

To evaluate the CRSS of diopside slip systems, we use the experimental data reported for crystals free of the so-called early-partialmelting (EPM) precipitates (Doukhan et al., 1993), since no EPM precipitation occurs at high pressure in diopside (Raterron et al., 1995). We use the rheological data from Raterron and Jaoul (1991), Jaoul and Raterron (1994), Raterron et al. (1994), and Amiguet et al. (2009). These authors studied three crystal orientations labeled [1], [2], [3], and [4] (see Table 2), which allow characterizing the activity of diopside known dislocation slip systems. A fully parameterized rheological law for crystal orientation [2] has been reported (Amiguet et al., 2009), and is used here to evaluate the CRSS of the duplex $1 / 2<1 \overline{1} 0>\{110\}$ systems (Table 2 ); the limited effect of varying $\mathrm{fO}_{2}$ on rheology ( $m \sim-0.2$ in Eq. (1); Jaoul and Raterron, 1994) is omitted, since it is only quantified in this crystal orientation. A partial rheological law for crystal orientation [4], which allows activating primarily [001]\{110\} system, is also reported (Raterron et al., 1994) although without quantification of the $n$ and $V^{*}$ parameters (Eq. 1); we use Amiguet et al. (2009)'s bi-crystal data (their Table 2 and Fig. 3a) to evaluate the latter parameters by comparison with those of the duplex systems. We obtain $n \sim 6.4$ and $V^{*} \sim 12 \mathrm{~cm}^{3} / \mathrm{mol}$, which complete this firstorder parameterization for $[001]\{110\}$ system flow law. [010](100) system has been activated in crystal orientation [3] $(S \sim 1 / 2)$, with negligible contribution of [100](010) system; yet, no rheological laws has been reported for this system. We thus use Amiguet et al. (2009)'s bi-crystal data (their Table 2 and
Fig. 3b) to evaluate [010](100) system $n$ parameter by comparison with that of the duplex systems; we obtain $n \sim 11.4$. Knowing $n$, we
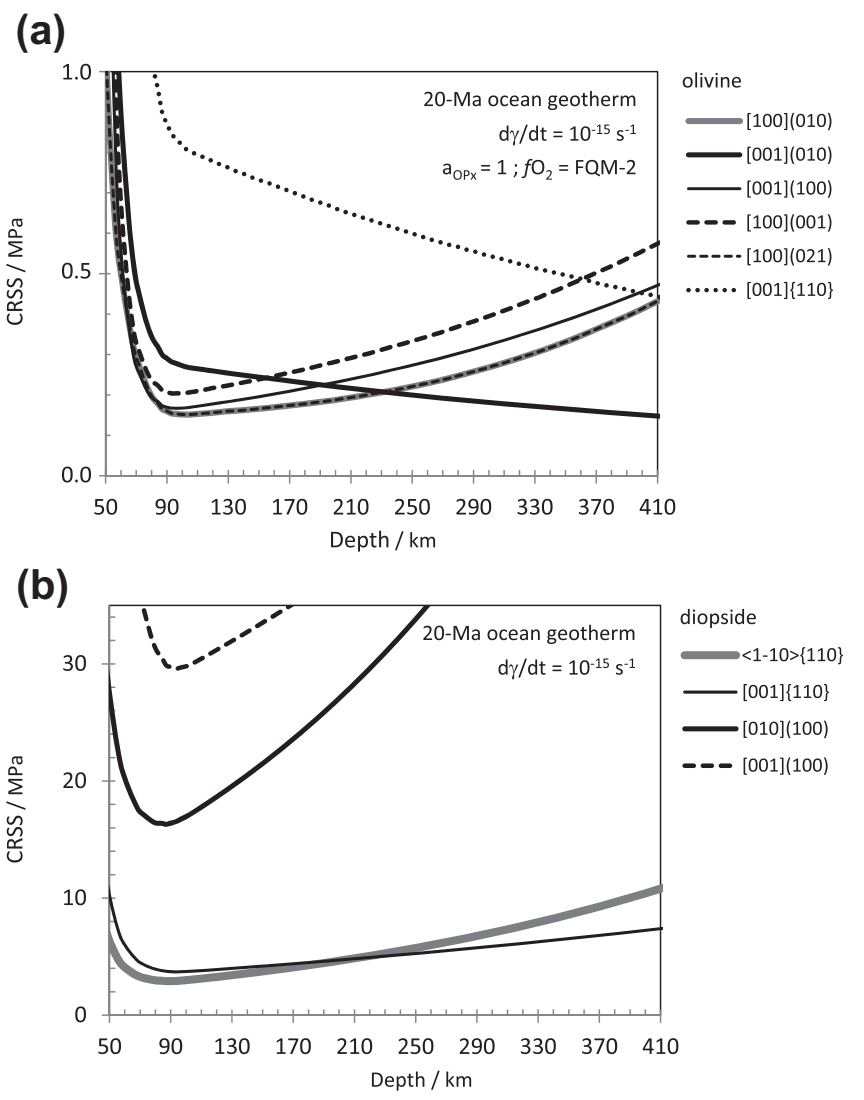

Fig. 1. CRSS of (a) olivine and (b) diopside slip systems versus depth (Table 1). Note olivine $P$-induced $[100] /[001]$ slip transition previously reported by several authors, between the easy $[100](010)$ and [001](010) slip systems, occurring $\sim 230 \mathrm{~km}$ depth. In diopside, a similar transition occurs at $\sim 210 \mathrm{~km}$ between $<110>/[001]$ slip in $\{110\}$ planes. Diopside is the hard phase in the aggregate, with estimated CRSS which are more than $\times 10$ higher than olivine CRSS. 
Table 2

Eq. (1) experimental parameters ${ }^{\dagger}$ used here for diopside slip systems.

\begin{tabular}{|c|c|c|c|c|c|}
\hline Crystal orientation & Activated slip system $^{+\dagger}$ & $\operatorname{Ln}(A)\left(\mathrm{MPa}^{-n} \mathrm{~s}^{-1}\right)$ & $n$ & $E^{*}(\mathrm{~kJ} / \mathrm{mol})$ & $V^{*}\left(\mathrm{~cm}^{3} / \mathrm{mol}\right)$ \\
\hline [2] & $1 / 2<1 \overline{1} 0>\{110\}$ & -7.8 & 6.46 & 442 & 17 \\
\hline [3] & {$[010](100)$} & -24 & 11.4 & 567 & 29 \\
\hline [4] & {$[001]\{110\}$} & -4.6 & 6.40 & 518 & 12 \\
\hline
\end{tabular}

$\dagger$ Crystal plasticity is assumed $\mathrm{fO}_{2}$ insensitive $(m=0)$; values in italics are estimates

$\dagger$ Slip-system CRSS is half $(S=1 / 2)$ the differential stress $(\sigma)$ at given condition.

evaluate the $A$ parameter from Raterron et al. (1994) by comparison with crystal orientation [2] data. Since no activation energy $E^{*}$ is reported for crystal orientation [3], we assume $E^{*} \sim 567 \mathrm{~kJ} / \mathrm{mol}$ by arbitrarily averaging the values reported for the other crystal orientations $(742,442$ and $518 \mathrm{~kJ} / \mathrm{mol}$, respectively for orientation [1], [2] and [4]) and finally adjust $V^{*}$ to account at best for orientation [3] deformation data. The Eq. (1) parameters resulting from the above consideration and use here for $1 / 2<1 \overline{1} 0>\{110\}$ systems, $[001]\{110\}$ and $[010](100)$ systems, are reported in Table 2. Let us emphasize that, although Table 2 parameters for [001] $\{110\}$ and $[010](100)$ systems account reasonably well for the deformation data reported thus far, they are mere first-order estimates which should not be considered as definitive values. More deformation data on diopside crystals in orientations [3] and [4] are needed to quantify accurately these parameters. However, in the framework of the present study, these experimentally-based parameters allow implementing the diopside phase in the modeling and testing the effect of a hard second phase on the modeled-aggregate plastic response.

[001](100) contribution to diopside plasticity is here quantified with respect to that of [001] $\{110\}$, using the results of Metsue et al. (2010) who calculated diopside slip-system Peierls stress at 0 and $10 \mathrm{GPa}$ from GSF energies (calculated from empirical potentials) coupled with the Peierls-Nabarro model. They report a Peierls stress significantly higher for [001](100) than for [001] $\{110\}$, with $\tau_{\mathrm{p}}$ ratios typically ranging from 5 to 12 depending on $P$ and the dislocation character (edge or screw). This result is consistent with transmission electron microscopy (TEM) investigation of deformed diopside (Raterron et al., 1994; Amiguet et al., 2010), which shows the predominance of the latter system with respect to the marginal former one. In the present modeling, we thus set [001](100) CRSS to 8 times that of [001]\{110\}, thus averaging the ratios of both systems $\tau_{\mathrm{p}}$. Finally, in the absence of criteria to set [100](010) CRSS, its negligible contribution to diopside deformation is omitted in the present model.

The CRSS for diopside slip systems, calculated at shear strain rate $\dot{\gamma}=\frac{1}{2} \dot{\varepsilon}=10^{-15} \mathrm{~s}^{-1}$ along a 20-Ma ocean geotherm - either from the flow laws reported in Table 2 or from the above theoretical considerations - are reported in Table 1 and plotted in Fig. 1 b.

\section{Self-consistent model for upper-mantle aggregates}

Predictions of polycrystal behavior can be obtained with meanfield homogenization methods. For linear behavior ( $n=1$ in Eq. 1$)$, the self-consistent (SC) model proposed by Kröner (1978) and Willis (1981) provides results in excellent agreement with full-field (FFT) results, for both 2-D and 3-D polycrystals (Lebensohn et al., 2005; Brenner et al., 2009). This model relies on a random geometrical grain arrangement exhibiting some specific statistical properties such as an infinite graduation of sizes (Milton, 1985). The deformation mechanisms are activated into modeled ellipsoidal inclusions of given crystallographic orientations, interacting with a homogeneous equivalent medium whose behavior represents that of the polycrystal, thus taking advantage of the analytical solution of Eshelby (1957) for inclusion/matrix interactions. The extension of the SC theory to non-linear viscoplasticity includes several technical difficulties; in particular a linearization that can critically affect the results and may lead to inconsistencies (Gilormini, 1996). A robust linearization method has been proposed in the early 2000s, leading to the second-order selfconsistent (SO) model (Ponte Castañeda, 2002) which has now been tested successfully against several 'reference' numerical solutions for various crystal symmetry (Lebensohn et al., 2007).

\subsection{Specifics of the present second-order (SO) model}

In the extension of the SO model for multi-phase materials reported here, each crystallographic phase $r$ (olivine or diopside, with set volume fractions) is decomposed into $\mathrm{N}^{\mathrm{r}}$ "mechanical phases" (representing set of "grains") with given lattice orientations. The local behavior of each mechanical phase (or "grain") depends on both its orientation and the crystal lattice symmetry. The macroscopic stress $\overline{\boldsymbol{\sigma}}$ and strain $\overline{\boldsymbol{\varepsilon}}$ tensors are the volume average of local stress $\boldsymbol{\sigma}(\mathbf{x})$ and strain $\boldsymbol{\varepsilon}(\mathbf{x})$ inside the polycrystal, with $(x)$ denoting the position. The extension of the SO model recently implemented by Detrez et al. (in preparation) accounts for the contribution of an isotropic relaxation mechanism to the polycrystal plasticity. This mechanism represents deformation mechanisms such those associated with 'diffusion-related' creep in olivine aggregates at high temperature. The local constitutive relation of a mechanical phase, at a scale smaller than the grain size, reads:

$\dot{\boldsymbol{\varepsilon}}(\mathbf{x})=\dot{\boldsymbol{\varepsilon}}_{\mathbf{d}}^{(\mathbf{r})}(\mathbf{x})+\sum_{\mathbf{k}=\mathbf{1}}^{\mathbf{N}^{\mathbf{r}}} \dot{\gamma}^{\mathbf{k}}(\mathbf{x}) \mu^{\mathbf{k}}(\mathbf{x})$

where $\dot{\varepsilon}_{d}^{(r)}$ is the strain rate due to the isotropic 'diffusion-related' mechanism of the rth crystallographic phase, $\dot{\gamma}^{k}(\mathbf{x})$ the slip rate in the kth slip system at position (x), and $\mu^{k}(\mathbf{x})$ the Schmid tensor of the corresponding slip system expressing the lattice orientation. The slip-rate $\dot{\gamma}^{k}(\mathbf{x})$ is given by:

$\dot{\gamma}^{k}(\mathbf{x})=\dot{\gamma}_{\mathbf{0}}\left(\frac{\tau^{\mathbf{k}}(\mathbf{x})}{\tau_{\mathbf{o}}^{\mathbf{k}}}\right)^{\mathbf{n}_{\mathbf{k}}}$

where $\dot{\gamma}_{0}$ is a reference slip rate, $n_{k}$ is the stress exponent of the kth slip system in the rth crystallographic phase, and $\tau^{k}(\mathbf{x})$ and $\tau_{0}^{k}$ are respectively the corresponding resolved shear stress at position (x) and the CRSS; here, $n=3.5$ for all olivine slip systems, and $n$ values for diopside slip systems are given in Table 2, while CRSS values calculated along a 20-Ma oceanic geotherm for all slip systems are reported in Table 1 . The strain rate associated with the isotropic mechanism (discarded here in diopside) is given in olivine by a linear flow rule:

$\dot{\boldsymbol{\varepsilon}}_{d}^{(r)}(\mathbf{x})=\frac{\dot{\epsilon}_{\mathbf{0}} \boldsymbol{\sigma}^{\prime}(\mathbf{x})}{\sigma_{\mathbf{0}}}$

where $\sigma_{0}$ and $\dot{\epsilon}_{0}$ are two adjustable rheological parameters; $\dot{\epsilon}_{0}$ is here set to $10^{-15} \mathrm{~s}^{-1}$, while adjusting $\sigma_{0}$ set the relative strength of the isotropic mechanism. $\dot{\boldsymbol{\varepsilon}}_{d}^{(r)}$ and $\boldsymbol{\sigma}^{\prime}$ are respectively the strain rate associated to the isotropic mechanism, and the deviatoric part of the Cauchy stress tensor. A temperature dependent rheology is 
(a)

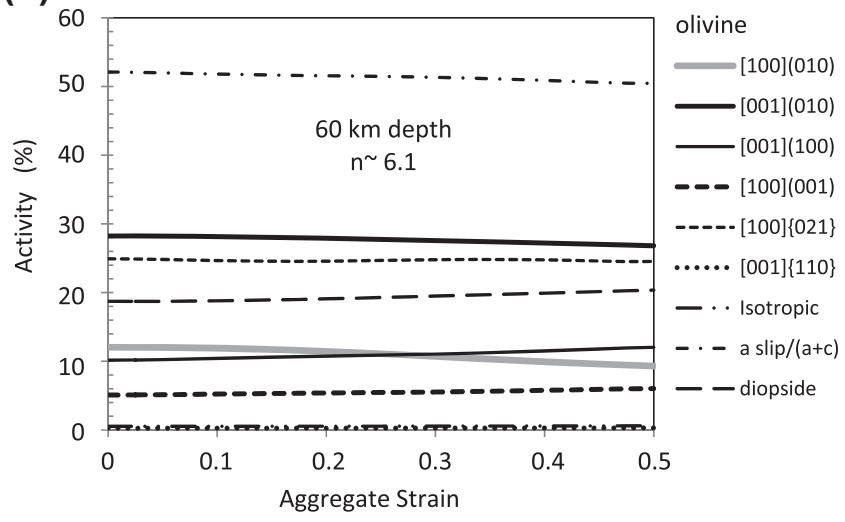

(b)

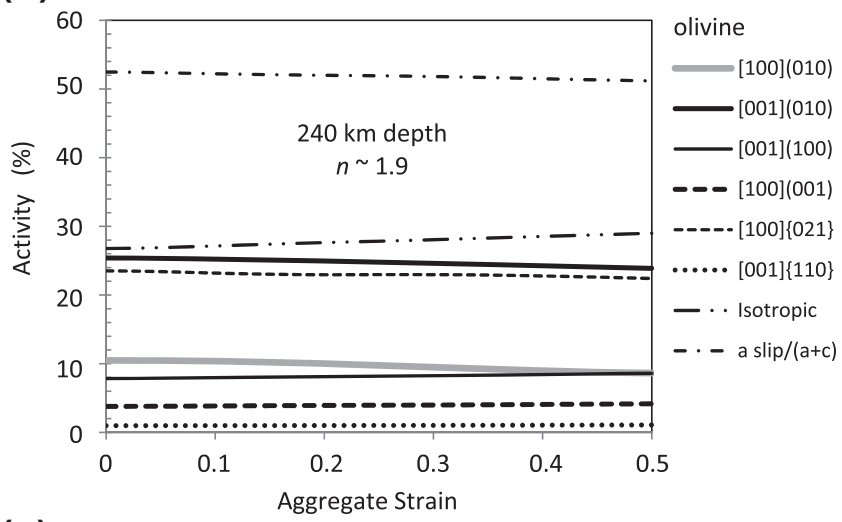

(c)

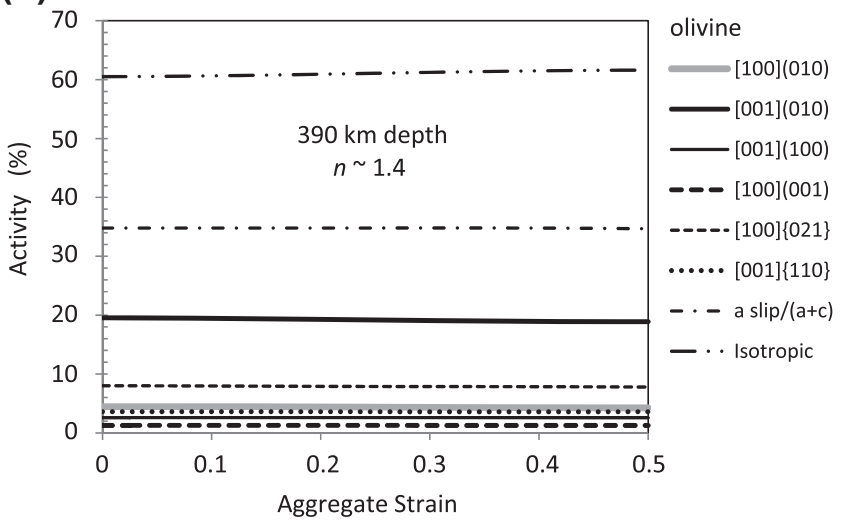

Fig. 2. Contribution of olivine deformation mechanisms to the strain of a $30 \mathrm{vol} . \%$ diopside aggregate sheared at $10^{-15} \mathrm{~s}^{-1}$, versus the aggregate strain at (a) $60-\mathrm{km}$, (b) $240-\mathrm{km}$ and (c) 390-km depth at along a 20-Ma ocean geotherm (Table 1). The average aggregate stress exponent $n$ is indicated. [100] dislocation relative activity with respect to all dislocation-slip activity (noted "a slip/( $\mathrm{a}+\mathrm{c})$ ") is also plotted, as well as at $60-\mathrm{km}$ depth diopside contribution to the aggregate strain.

implemented for the isotropic mechanism, and is specialized across the $\sigma_{0}$ term by the Arrhenius relationship:

$\sigma_{0} \propto \exp \left(\frac{Q_{0}}{R T}\right)$

where $Q_{0}$ is the activation energy. Since 'diffusion-related' mechanisms in olivine are mostly controlled by the mobility of silicon cations, we use the activation energy $\mathrm{Q}_{0}=530 \mathrm{~kJ} / \mathrm{mol}$ reported for $\mathrm{Si}$ self-diffusion in olivine (Dohmen et al., 2002). Si diffusion in San Carlos olivine is virtually pressure insensitive (Béjina et al., 1997, 1999), hence no $P$ effect is implemented here for the isotropic relaxation mechanism. (a)

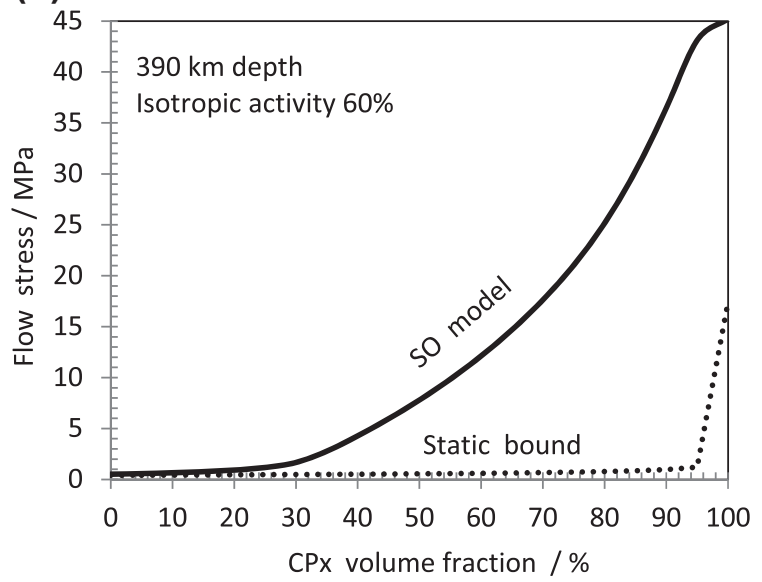

(b)

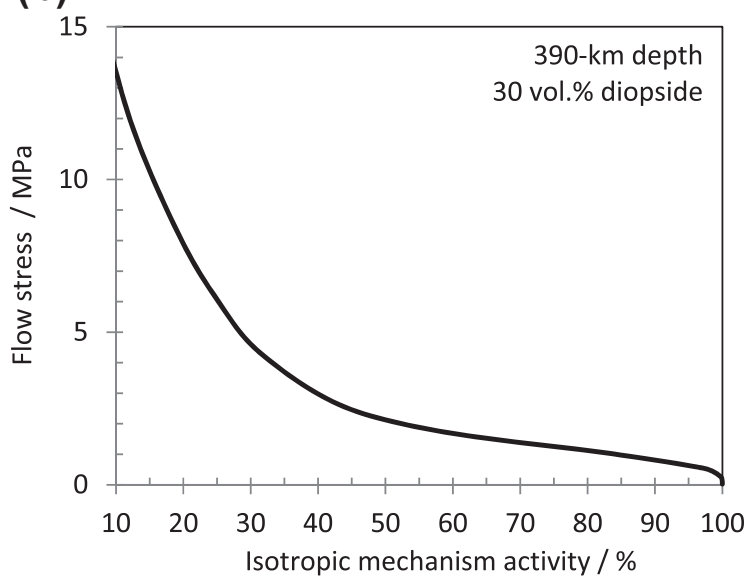

(c)

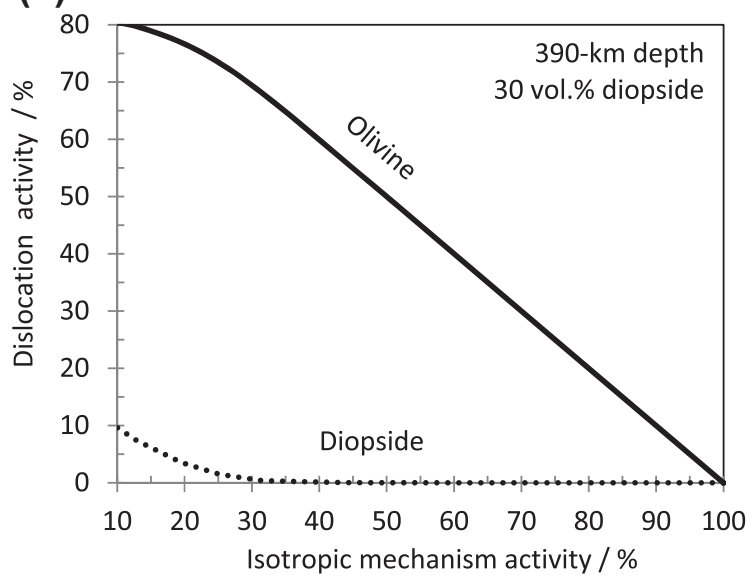

Fig. 3. Mechanical behavior for olivine/diopside aggregate for conditions matching $390 \mathrm{~km}$ depth (Table 1). (a) Flow stress vs. diopside volume fraction. Solid line, SO self-consistent approximation, dashed line, uniform stress approximation (Sachs, 1928). Isotopic mechanism activity fixed to 60\%. (b) Aggregate flow stress and (c) relative activities of olivine and diopside dislocation slips vs. isotopic mechanism activity for an aggregate with 30 vol.\% of diopside.

Let us highlight here some limitations of the present model: because of the chosen isotropic assumption for the 'diffusion-related' mechanism, the model does not account for grain rotation linked with diffusion creep; such rotations can be accounted for using different numerical approaches (e.g., Ford et al., 2002) and may be relevant for the preservation or destruction of seismic anisotropy in mantle rocks (Wheeler, 2009). The formation of LPO during 
linear-viscous (newtonian) creep has also been experimentally observed in anorthite and forsterite aggregates (Gómez Barreiro et al., 2007; Miyazaki et al., 2013); the mechanism responsible for such LPO formation, likely 'diffusion related' although still unclear, is not accounted for in the present model. Along the same line, diffusion creep in two phase aggregates shows some quite odd behaviors, as predicted by early modeling (Wheeler, 1992) and recently observed in experimentally deformed harzburgite (Sundberg and Cooper, 2008); such behaviors cannot be described in the framework of the present modeling. Finally, anisotropic grain-boundary diffusion, likely related to grain shapes and size (Wheeler, 2010) which are not detailed in mean-field models, cannot be addressed here. Hence, the isotropic 'diffusion-related' mechanism implemented here, although resembling the Nabarro-Herring diffusion, does not represent specific diffusion mechanisms; it is a general term to account in the SO model for the thermally activated linear-viscous mechanisms which are not associated with dislocation motions.

\subsection{Olivine + diopside aggregate plasticity at mantle conditions}

Olivine and diopside slip-system CRSS (Table 1) are implemented into the improved SO model described above. The advantage of this approach is that the model parameters are based on a physical description of the deformation mechanisms, which are here treated individually while scaling their plastic responses to mantle conditions. In the present application, a 70 vol.\% olivine +30 vol.\% diopside aggregate is deformed in simple shear to a maximum shear strain $\gamma=0.5$, at shear strain rate $\dot{\gamma}=10^{-15} \mathrm{~s}^{-1}$ representative of natural deformations. The aggregate viscoplastic response to this deformation is calculated at conditions corresponding to 60, 240 and 390-km depths along a 20-Ma ocean geotherm $\left(\mathrm{fO}_{2}=\mathrm{FQM}-2\right.$, see Table 1$)$; pressure increase with depth is here calculated using upper mantle average density $\left(3.35 \mathrm{~g} / \mathrm{cm}^{3}\right)$, i.e. a $32.9 \mathrm{MPa} / \mathrm{km}$ pressure gradient, while temperature follows a typical gradient (see Raterron et al., 2012, their Fig. 2a) reaching at $\sim 100 \mathrm{~km}$ depth the classical adiabat (Turcotte and Schubert, 2002, p. 187). At each depth, calculations are performed using the CRSS reported in Table 1 for each olivine and diopside slip system (see Sections II.1 and II.2).

To adjust the strength of the model isotropic mechanism, we use the recent experimental results of Bollinger (2013) which show that less than $\sim 40 \%$ of olivine aggregate strain at high temperature may be accommodated by free dislocation motions within grains. In other words, more than $\sim 60 \%$ of the aggregate strain may be accommodated by other deformation processes, such as Cobble diffusion and grain boundary sliding operating at grain boundary, or Nabarro-Herring diffusion within grains. As mentioned above, the model isotropic 'diffusion-related' mechanism does not represent specific deformation processes in the aggregate; it is, however, a thermally activated process allowing producing strain without resorting to dislocation motions. We thus set arbitrarily to 60\% the contribution to the aggregate strain (the activity) of the isotropic mechanism at $T=1749 \mathrm{~K}$, i.e. at $390-\mathrm{km}$ depth in the Earth, leaving the rest of the aggregate strain ( 40\%) accommodated by dislocation slips. The activity of the isotropic mechanism at shallower depths is then controlled by the $T$ dependence of Si diffusion in olivine (Eqs. 4 and 5), i.e., it decreases with decreasing $T$ at shallower depths.

Let us point out here that, although arbitrary, the adjustment in the modeling of the activity of the 'diffusion-related' isotropic mechanism can be partly constrained by experimental and theoretical considerations. In real mantle aggregates, the activity of diffusion processes (Cobble diffusion, Nabarro-Herring diffusion, etc.) depends on the aggregate grain size $(d)$; the smaller the grain size, the higher the proportion. Because dynamic recrystallization occurs at high temperature in olivine, grain size and differential stress follow a piezometric relationship (Ross et al., 1980). In aggregates deforming at high temperature, the activity of diffusion processes, the grain size and the flow stress are, thus, interdependent parameters. In the modeling, one cannot input a grain size; yet one can adjust the relative strength of the isotropic mechanism, hence its activity, which directly affects the flow stress (an output of the computation). Therefore, adjusting the output flow stress at given deformation conditions $\left(P, T, \mathrm{fO}_{2}\right.$ and strain rate) consists in adjusting the activity of the isotropic mechanism. Conversely, adjusting this activity at given conditions imposes the flow stress, which in real deforming aggregates also imposes the average grain size because of the piezometric relationship.

Bollinger (2013) reports that less than $40 \%$ of strain may be accommodated by dislocation creep in experiments carried out at typically $\sigma \sim 500 \mathrm{MPa}$, on olivine aggregates with average grain size $d \sim 5-10 \mu \mathrm{m}$. Using a stress-grain size scaling law as that reported by Ross et al. (1980) - where $d$ (in $\mu \mathrm{m}$ ) is proportional to $\sigma-1.27$ ( $\sigma$ in kbar) - we find that these conditions correspond for the grain size estimated in the deep upper mantle $(d \sim 1 \mathrm{~cm})$ to differential stresses of a few MPa, i.e. in the range of the flow stress estimated in the deep upper mantle (a review in Bürgmann and Dresen, 2008). The activity of dislocation glide in Bollinger's experiment ( $40 \%)$ may, thus, be representative of that prevailing in the deep upper mantle. It is therefore reasonable to set in the model at $40 \%$ the activity of dislocation creep at $390-\mathrm{km}$ depth, i.e. to set at $60 \%$ that of the isotropic 'diffusion-related' mechanism. This proportion, however, can be easily adjusted to account for future more accurate experimental quantifications.

Fig. 2a, b, and c show the contribution to the aggregate strain (the 'activity') of deformation mechanisms versus the aggregate strain, as obtained from the modeling at 60, 240 and $390-\mathrm{km}$ depths (Table 1 ). Also reported in these figures is the total activity of all slip systems with a [100] Burgers vector (noted "a slip/ $(a+c)$ ") with respect of the total activity of dislocation slip in olivine. Fig. 2a shows that the isotropic-mechanism activity at $60 \mathrm{~km}$ is extremely low $(<0.6 \%)$, and increases with depths to reach the imposed $\sim 60 \%$ at $390 \mathrm{~km}$ (Fig. 2c); this accounts well for the increasing activity with $T$ of 'diffusion-related' processes in the deforming aggregate. The contribution of diopside plasticity to the aggregate strain is significant at $60 \mathrm{~km}(\sim 20 \%$, Fig. $2 \mathrm{a})$, but is very small at higher depth ( $<2 \%$, not represented). Let us note that both effects, i.e. the increasing isotropic-mechanism activity and decreasing diopside plasticity with depth, translates into a steady decrease with depth of the aggregate apparent stress sensitivity, from $n \sim 6.1$ at $60 \mathrm{~km}$ to $n \sim 1.4$ at $390 \mathrm{~km}$. At $240-\mathrm{km}$ depth, the aggregate $n \sim 1.9$ is consistent with a mixed rheology where "diffusion related' mechanisms contribute significantly to the aggregate strain (here with an activity $\sim 35 \%$ ). Assuming different stress sensitivities in the dislocation creep regime for olivine crystals (here $n=3.5$ ) and diopside crystals (see Table 2) would affect the $n$ values obtained for the modeled aggregate; yet the aggregate $n$ would still decrease while 'diffusion-related' mechanism (with $n=1$ ) become more efficient with increasing temperature. Regarding olivine slip-system activities: [100] dislocation relative activity (a-slip/(a+c)) is higher than $50 \%$ at depth $\leqslant 240 \mathrm{~km}$, while the [100]/[001] slip-transition depth occurs at $\sim 230 \mathrm{~km}$ (Table 1 and Fig. 1); it drops to $\sim 35 \%$ at $390-\mathrm{km}$ depth where [001] slip is dominant. At low pressure $(60 \mathrm{~km})$, most of the [100] glide activity is primarily due to [100]\{021\} systems (activity 25\%) and $[100](010)$ system (activity $\sim 11 \%$ ); these easy systems have the same CRSS in the model, and their respective activities are mostly explained by the numbers of available glide planes (respectively, 2 and 1$)$. Let us note that, at all depths, [001](010) system has the highest activity among slip systems, a results partly 
explained by the relatively low activities of the other [001] slips; among them, [001] $\{110\}$ has the lowest activity of all olivine deformation mechanisms because of its high CRSS (Fig. 1, Table 1).

Fig. 3a shows the aggregate flow stress at 390-km depth obtained from the SO model versus diopside volume fraction. As expected in 'real' bi-phase aggregates (Ji et al., 2001), the flow stress increases with increasing fraction of the hard phase (diopside); a result which does not arises from simpler model, e.g. from the Sachs (1928) uniform stress approximation ('Static bound' curve in the figure) resulting in a deformation mostly accommodated by the soft phase (olivine). Let us note that the model flow stress at diopside fraction $<30 \mathrm{vol} . \%$ ( $<1.7 \mathrm{MPa}$ ) is reasonable when compared with reported estimates for mantle flow stresses (typically from 0.1 MPa to a few MPa; e.g., Bürgmann and Dresen, 2008; Barnhorrn et al., 2011). However, as mentioned above, the aggregate flow stress strongly depends on the imposed activity for the isotropic mechanism, as illustrated in Fig. 3b at 390-km depth for a 30 vol.\% diopside aggregate. A reasonable flow stresses $(<2 \mathrm{MPa})$ can only be obtained with an isotropic-mechanism activity $>50 \%$, suggesting that 'diffusion-related' mechanisms play a significant role in the deep upper mantle. The 30 vol.\% diopside present in the aggregate has no bearing on this results since, at isotropic-mechanism activity $\sim 30 \%$ or higher, diopside crystals do not contribute to the aggregate plasticity (Fig. 3c), i.e., they behave like rigid inclusions in a soft olivine matrix.

Fig. 4a shows olivine pole figures at shear strain $\gamma=0.5$ obtained from the modeling at different depths along a 20-Ma ocean geotherm. At $60-\mathrm{km}$ depth, it shows a strong 010 pole pseudoperpendicular to the shear plane, with marked 100 pole (the fast velocity axis) sub-parallel to the direction of shear, which is consistent with the classic olivine LPO observed in dry low-P experiments and many geological contexts (e.g., Boullier and Nicolas, 1975; Tommasi et al., 1999; Bystricky et al., 2000). A similar LPO is obtained at $240-\mathrm{km}$ depth, although not as marked. At 390-km depth, however, the larger activities of both [001] slip and of the isotropic mechanism (Fig. 2) results in significant changes in the obtained pole figure; it exhibits a weak 010 pole pseudo-perpendicular to the shear plane and a weak 001 pole sub-parallel to the shear direction. Such olivine LPO at low and high $P$ are in good agreement with deformation experiments on dry olivine aggregates (e.g., Ohuchi et al., 2011) and with interpretations of seismic anisotropy attenuation in the deep (dry) upper mantle (e.g., Mainprice et al., 2005; Ohuchi and Irifune, 2013).

Fig. 4b shows diopside pole figures at shear strain $\gamma=0.5 \mathrm{ob}-$ tained from the modeling at different depths along a 20-Ma ocean geotherm. At $60-\mathrm{km}$ depth, it shows a strong 010 pole pseudo-perpendicular to the shear plane, with marked 001 pole sub-parallel to the direction of shear. In diopside monoclinic geometry, [001] direction is at $15.8^{\circ}$ from 001 pole. Such a LPO was previously obtained with an earlier visco-plastic self-consistent formulation (socalled 'VPSC model' in the literature) for CPx aggregate (Bascou et al., 2001, 2002) and is consistent with the classic LPO observed in naturally deformed eclogites (e.g., Godard and Van Roermund, 1995). This LPO tends to promote a fast velocity axis sub-parallel to the shear direction (along [001] direction) and a low velocity axis sub-perpendicular to the shear plane (along 010 pole). Let us emphasize, however, that CPx anisotropy for S-wave propagation exhibits complex features (e.g., Bascou et al., 2001) which can be counterintuitive: for instance, the anisotropy along [010] may dramatically increase with $P$ (Walker, 2012). At depth $\geqslant 240 \mathrm{~km}$, however, diopside does not present any LPO, since at these depths CPx crystal deformation is negligible (Fig. 3c).

\section{Discussion}

The present results show that coupling state-of-the-art meanfield micromechanical modeling for aggregate plasticity, with experimental and theoretical data on mineral deformation mechanisms, allows to reasonably constrain the response of upper-mantle aggregates deformation at a given strain rate. The olivine and diopside LPOs reported here at shallow depth $(60 \mathrm{~km})$ are consis-
100
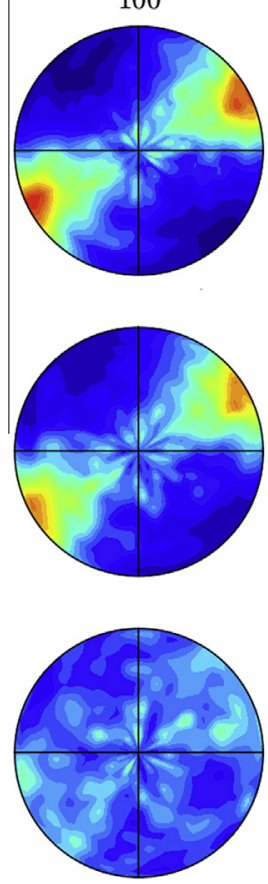

010
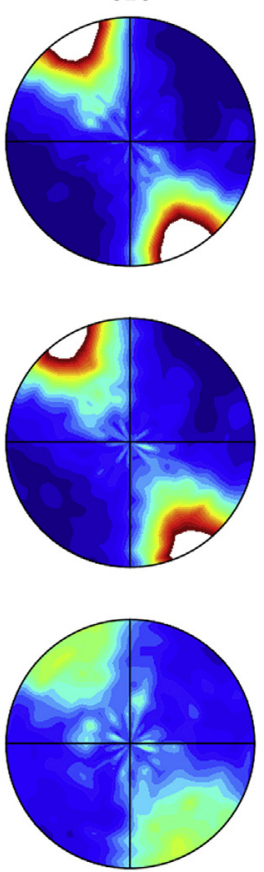

001

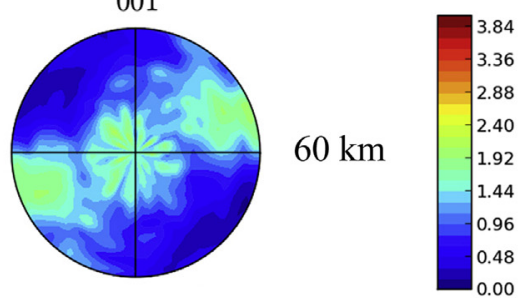

$369[$ phi,th] grid $15^{\circ}$ spread

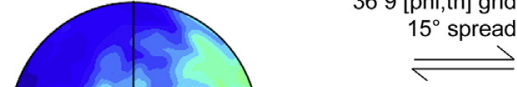

$240 \mathrm{~km}$

$390 \mathrm{~km}$

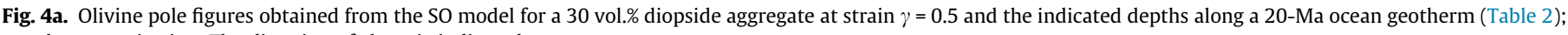
equal-area projection. The direction of shear is indicated. 
100
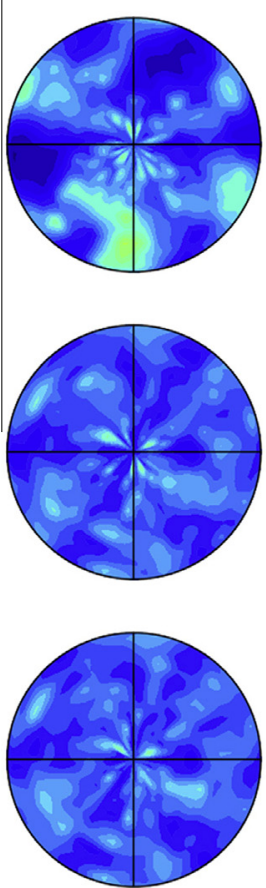

010
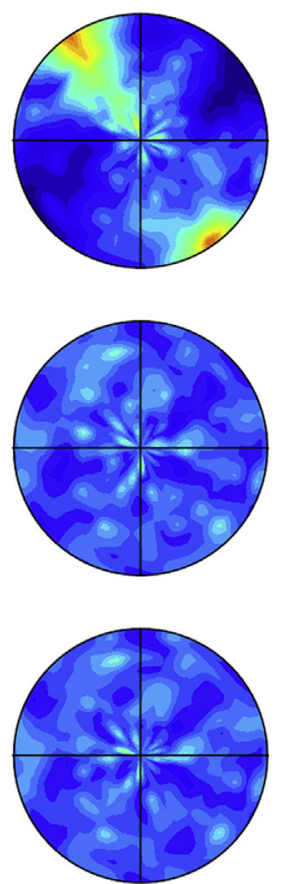

001
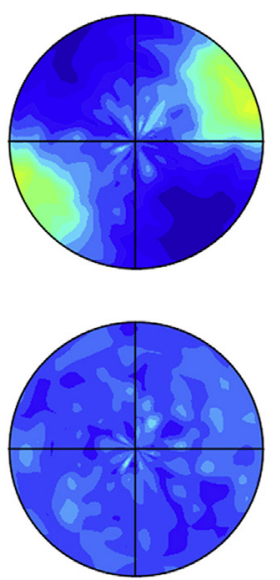
$15^{\circ}$ spread

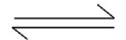

$240 \mathrm{~km}$

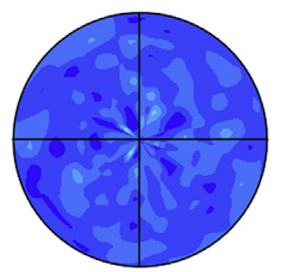

3.84
-3.38
-2.91

$60 \mathrm{~km}$

$-1.97$

$-1.50$

1.03

0.10
$390 \mathrm{~km}$

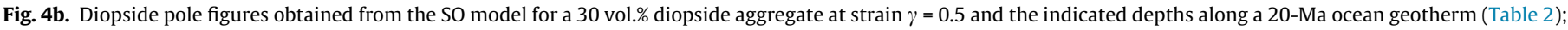
equal-area projection. The direction of shear is indicated.

tent with the ones observed in naturally deformed rocks and after deformation experiments. At that depth, the activity of the model ad hoc isotropic deformation mechanism is extremely low $(<0.6 \%)$, i.e., most of the aggregate viscoplastic response relies on Table 1 parameters, which arise from experiments on single crystals and GSF energy calculation coupled with the Peierls-Nabarro model. Some of these parameters can and will be refined, but they already provide a framework for investigating the plasticity of upper mantle rocks, and scale it to natural conditions of deformation.

The isotropic mechanism is here adjusted in the model to account for $60 \%$ of the aggregate strain at $390-\mathrm{km}$ depth; its activity at shallower depth is constrained by the thermal activation of Si diffusion in olivine. Such a high activity for 'diffusion-related' mechanisms at high temperature is reasonable, since it is observed in experiments carried out at high stress on fine-grain CPx or olivine aggregates (Bystricky and Mackwell, 2001; Bollinger, 2013) given the grain size vs. flow stress piezometric relationship in olivine (Mercier et al., 1977; Ross et al.,1980), one may speculate that 'diffusion-related' mechanisms have similar activities in the larger grain-size and lower-stress regime of natural deformations. With an activity of $60 \%$, we obtain a flow stress of $1.7 \mathrm{MPa}$ for a 30 vol.\% diopside aggregate sheared at $\dot{\gamma}=10^{-15} \mathrm{~s}^{-1}$. This flow stress is reasonable when compared to the flow-stress estimates for the deep upper mantle, typically between 0.1 and a few MPa (a review in Bürgmann and Dresen, 2008; see also, Gasperimi et al., 2004, and Barnhorrn et al., 2011). It can be adjusted in the present model by varying the relative strength of the isotropic mechanism, hence its contribution to the aggregate strain at reference conditions (Fig. 3b). Interestingly, the model cannot account for stress estimates in the deep upper mantle without a significant contribution of the isotropic mechanism to the aggregate strain. Since the other deformation mechanisms, mostly olivine dislocation slip systems, are constrained by their physical properties - i.e., their activities at given conditions are imposed by the physics underlying them we conclude that 'diffusion-related' mechanisms must take a significant part of peridotite deformation in the deep upper mantle. Such composite dislocation creep + diffusion creep behavior has been proposed recently to interpret mantle postglacial rebound and viscosity variations in the mantle (e.g., Gasperimi et al., 2004; Barnhorrn et al., 2011). The present model provides a tool based on experimental and computational data to quantify the respective activity of dislocation creep and diffusion creep in the mantle.

Among possible 'diffusion-related' mechanisms, the 'classic' diffusion creep, i.e., Coble creep and Nabarro-Herring creep, was proposed by Karato (1992) for the deep upper-mantle plasticity. In the present model $\sim 40 \%$ of the aggregate strain is, however, still produced by dislocation motions at 390-km depth (Fig. 2c). De Bresser et al. (1998) suggested that dynamic recrystallization (DRX) in well-equilibrated Earth-materials aggregates results in a deformation regime occurring at the boundary between the dislocationcreep and diffusion-creep fields (see also, De Bresser et al., 2001), i.e. with a comparable activity from both 'diffusion-related' creep and dislocation creep. If this is the case in the upper mantle, the model isotropic-mechanism activity could be adjusted to $~ 50 \%$ of the aggregate strain and allow estimating mantle stresses in given geodynamical context. More recently, Hansen et al. (2011) identified dislocation-assisted grain-boundary sliding (called GBS) in olivine aggregates deformed experimentally at high temperature (see also Hansen et al., 2012); a mechanism which produces a significant amount of strain at grain boundary by 'diffusion-related' mechanisms, yet promotes dislocation motions within the crystal bulk. It is unclear whether GBS is an active mechanism at mantle pressure, and which proportion of strain is accommodated by dislocation motions during GBS. Nevertheless, if the activity of olivine dislocation glide during GBS could be further quantified, it could be accounted for in the present model which would provide a tool to scale experimental results to mantle conditions.

Let us also note that the aggregate apparent stress exponent $n$ (Eq. 1) depends strongly on the respective activities of the deformation mechanisms: it is here high $(n \sim 6.1)$ at $60-\mathrm{km}$ depth - where the aggregate deformation occurs mostly by dislocation creep with a significant contribution from diopside plasticity - and much low- 
er $(n \sim 1.4)$ at $390 \mathrm{~km}$ where the viscous-linear isotropic mechanism accounts for $60 \%$ of the aggregate strain. The $n$ parameter (together with the grain-size sensitivity of the strain rate) has been extensively used in the literature to identify aggregate deformation regime: $n \sim 1$ or $\sim 3$ in olivine roughly corresponding to the diffusion-creep or the dislocation-creep regime, respectively; intermediate $n$ values have been attributed to mixed or transient regimes of deformation. The present model provides an useful tool to test such criteria, particularly in the mixed regime of deformation for multiphase-aggregate which cannot be quantified using traditional ad hoc micro-modeling of the involved mechanisms (e.g., Poirier, 1985).

The present results provide constraints on the transition(s) underlying the seismic anisotropy attenuation observed in the deep upper mantle (e.g., Gung et al., 2003). This attenuation, occurring at depth typically $>200 \mathrm{~km}$, has been attributed to a transition from diffusion creep to dislocation creep (Karato, 1992), and more recently to the $P$-induced $[100] /[001]$ slip transition in olivine (Mainprice et al., 2005; Ohuchi et al., 2011; Ohuchi and Irifune, 2013). The weakening of olivine LPO with depth arising from the present model is consistent with mantle seismic anisotropy attenuation. Here, it results from both the [100]/[001] slip transition (Fig. 1a) and the increasing activity of 'diffusion-related' mechanisms in the deep upper mantle (see above and Fig. 2); the former transition favors an LPO with 001 pole along the shear direction, while the latter limits the development of a strong LPO since diffusion is isotropic in the model. The present results, thus, provide a first quantification of the respective effects of both phenomena, i.e., [1 00]/[001] slip transition and diffusion creep, on olivine vanishing LPO in the deep upper mantle.

Our results give insight on the effect of a hard second phase on an aggregate plasticity. The SO-model curve on Fig. 3a is in good agreement with the flow-stress dependence on increasing volume fraction of a hard phase, as measured experimentally by Ji et al. (2001) for enstatite + forsterite aggregates (see their Fig. 7). It shows that for low fractions of the hard phase (here diopside) the aggregate strain is mostly accommodated by the soft phase (here olivine), and at higher fractions (here $\geqslant 30$ vol.\%) the flow stress increases steeply with the hard-phase fraction. Such behavior is well reproduced here, which gives us confidence in the present extension of the SO model to multiphase aggregate plasticity. The aggregate strength obtained at $390 \mathrm{~km}$ for a $100 \%$ diopside aggregate ( $\sim 45 \mathrm{MPa})$ strongly depends of Table 2 parameters no isotropic mechanism is implemented in diopside - which need to be refined by further experiments and computations. Discussing diopside-aggregate stress is, thus, speculative. Let us note, however, that a much lower stress $(\sim 0.4 \mathrm{MPa})$ is obtained when using the flow law (Eq. 1) reported by Bystricky and Mackwell (2001) for dry large-grain CPX aggregate deformed at low pressure. Besides uncertainties on Table 2 parameters, such a flow-stress discrepancy can be resolved by implementing either an active 'isotropic mechanism' in the modeled diopside aggregate, or a significant $P$ sensitivity (i.e., an apparent $V^{*} \sim 28 \mathrm{~cm}^{3} / \mathrm{mol}$ ) in Bystricky and Mackwell's flow law. Finally, Fig. 4b shows that diopside does not exhibit LPO at depth $\geqslant 240 \mathrm{~km}$, because of the very small activity of its slip systems $<2 \%$ and $<0.02 \%$ at 240 and $390 \mathrm{~km}$, respectively. In other words, at high pressure and temperature, diopside crystals behave as rigid inclusions within a soft olivine matrix which prevents the development of LPO. Diopside represents $\sim 10$ vol.\% of upper-mantle lherzolites, and this fraction is lower in the deep upper mantle. It is thus unlikely that diopside contributes significantly to the deep upper-mantle seismic anisotropy. However, the strong CPX LPO reported here at shallow depth $(60 \mathrm{~km})$, with a fast velocity axis sub-parallel to the shear direction, may significantly increase the anisotropy of deformed lithospheric peridotites and eclogites.

\section{Conclusion}

Following Castelnau et al. (2010), the multiscale modeling reported here for upper mantle plasticity is constrained by the physics underlying deformation mechanisms in minerals, as quantified experimentally or calculated from theoretical considerations. Unlike the earlier VPSC scheme (which could not, due to its inherent formulation, account for mechanisms exhibiting different stress exponents), the present SO model is 'truly' multiscale in the sense that its parameterization accounts for first-principle calculation of dislocation-core energy at the atomic scale, measured individual slip-system CRSS at the mineral scale, stress and strain compatibilities at the aggregate scale, and accurate description of the mechanical interactions between deforming grains. We present here a first application of an extension of the SO-model (Detrez et al., in preparation), to a multiphase (olivine + diopside) polycrystal deformed at $10^{-15} \mathrm{~s}^{-1}$ shear strain rate along a 20-Ma ocean geotherm. This model is well adapted for highly non-linear materials such as silicates and integrates 'diffusion-related' mechanisms through the implementation of a thermally-activated isotropic deformation mechanism, which activation energy matches that of Si diffusion in San Carlos olivine. No fictitious slip systems are implemented here, and the only ad hoc parameter is the relative strength of the isotropic mechanism; it is here adjusted to account for recent experimental observations on the respective contributions of intracrystalline vs. grain-boundary deformation mechanisms to olivine aggregate strain (Bollinger, 2013). The main conclusions of this work are:

i) The olivine and diopside LPOs obtained from the model at shallow depth (60 km), where the isotropic-mechanism contribution is minimal, are in good agreement with the LPOs produced experimentally or observed in naturally deformed rocks; this is remarkable since, as mentioned above, the model slip-system parameters (CRSS and stress sensitivities) are all constrained by experiments and/or theoretical calculations.

ii) The sensitivity of the modeled-aggregate strength to the volume fraction of the hard phase (diopside) and to the relative activities of the involved mechanism (i.e., diffusion vs. dislocation) reproduces well experimental results. At low volume fraction (here $\leqslant 30$ vol.\% diopside) most of the strain is accommodated by the soft phase (olivine), while at higher volume fraction the aggregate strength increases steeply with the proportion of the hard phase; and the aggregate apparent $n$ exponent (Eq. 1 ) is sensitive to dislocation-slip and the linear-viscous isotropic mechanism relative activities.

iii) The flow stress obtained from the model at 390-km depth for a 30 vol.\% diopside aggregate, assuming that the isotropic mechanism activity is $\sim 60 \%$, is in good agreement with stress estimates in the deep upper mantle; however, decreasing the activity of the isotropic mechanism leads to unrealistic flow stresses. This shows that dislocation creep alone cannot account for the flow stress estimated in the deep upper mantle; i.e., other 'diffusion-related' deformation mechanisms likely contribute to the deep upper-mantle plasticity.

iv) In a 30 vol.\% diopside aggregate, the CPx LPO vanishes at depth $\geqslant 240 \mathrm{~km}$ because of the increasing strength contrast between olivine and diopside at high temperature and pressure, i.e., diopside crystals tend to behave as rigid inclusions in a soft olivine matrix.

v) The model shows a significant weakening of olivine LPO at depth $\geqslant 240 \mathrm{~km}$, which is due to both the $P$-induced [100]/[001]-slip transition and the increasing activity of 
'diffusion-related' creep with temperature; this result thus provides a physics-based explanation for the seismic anisotropy attenuation observed in the deep upper mantle.

\section{Acknowledgements}

We wish to express our profound gratitude to Robert C. (Bob) Liebermann (Stony Brook University) for decades of dedication, training and collaborating with young researchers - among which numerous French scientists - and giving them access to state-ofthe-art high-pressure equipments. Without the scientific, technical and administrative environment provided over the years by CHiPR and the COMPRES consortium (http://compres.us/), to which Bob contributed greatly, this work would not have been possible. We are also thankful to two anonymous reviewers whose in-depth comments and suggestions help improving the original manuscript. This research was supported by the Agence Nationale de la Recherche (ANR) Grant BLAN08-2_343541 "Mantle Rheology”.

\section{References}

Amiguet, E., Raterron, P., Cordier, P., Couvy, H., Chen, J., 2009. Deformation of diopside single crystal at mantle pressure, 1, Mechanical data. Phys. Earth Planet. Int. 177, 122-129.

Amiguet, E., Cordier, P., Raterron, P., 2010. Deformation of diopside single crystals at mantle pressure. TEM characterization of dislocation microstructures. Eur. J. Miner. 22, 181-187.

Avé Lallemant, H., 1978. Experimental deformation of diopside and websterite. Tectonophysics 48, 1-27.

Bai, Q., Kohlstedt, D.L., 1992a. High-temperature creep of olivine single crystals. 2. Dislocation microstructures. Tectonophysics 206, 1-29.

Bai, Q., Kohlstedt, D.L., 1992b. High-temperature creep of olivine single crystals.III. Mechanical results for unbuffered samples and creep mechanisms. Phil. Mag. 66 (6), 1149-1181.

Bai, Q., Mackwell, S.L., Kohlstedt, D.L., 1991. High-temperature creep of olivine single crystals.1. Mechanical results for buffered samples. J. Geophys. Res. 96, 2441-2463.

Barnhorrn, A., Van der Wal, W., Vermeersen, B.L.A., Drury, M.R., 2011. Lateral, radial and temporal variations in the upper mantle viscosity and rheology under Scandinavia. Geochem. Geophys. Geosyst. 12 (1), Q01007. http://dx.doi.org/ 10.1029/2010GC003290.

Bascou, J., Barruol, G., Vauchez, A., Mainprice, D., Egydio-Silva, M., 2001. EBSD measured lattice-preferred orientations and seismic properties of eclogites. Tectonophysics 342, 61-80.

Bascou, J., Tommasi, A., Mainprice, D., 2002. Plastic deformation and development of clinopyroxene lattice preferred orientations in eclogites. J. Struct. Geol. 24, 1357-1368.

Béjina, F., Raterron, P., Zhang, J., Jaoul, O., Liebermann, R.C., 1997. Activation volume of silicon diffusion in San Carlos olivine. Geophys. Res. Lett. 24 (21), 2597-2600.

Béjina, F., Jaoul, O., Liebermann, R.C., 1999. Activation volume of Si diffusion in San Carlos olivine: implications for upper mantle rheology. J. Geophys. Res. 104 (B11), 25,529-25,542.

Bollinger, C., 2013. Rhéologie de l'olivine polycristalline aux conditions du manteau supérieur: étude en D-DIA, PhD Thesis \# 41140, Université Lille 1 - Sciences et Technologies, p. 105, France.

Bollinger, C., Merkel, S., Raterron, P., Cordier, P., 2013. Olivine dislocation creep: revisiting experimental data to 8 GPa pressure. Phys. Earth Planet. Int., in press.

Boullier, A.M., Nicolas, A., 1975. Classification of textures and fabrics of peridotite xenoliths from South African kimberlites. Phys. Chem. Earth 9, 467-468.

Brenner, R., Lebensohn, R., Castelnau, O., 2009. Elastic anisotropy and yield surface estimates. Int. J. Solids Struct. 46, 3018-3026.

Bürgmann, R., Dresen, G., 2008. Rheology of the lower crust and upper mantle: evidence from rock mechanics, geodesy and field observations. Annu. Rev. Earth Planet. Sci. 36, 531-567.

Bystricky, M., Mackwell, S., 2001. Creep of dry clinopyroxene aggregates. J. Geophys. Res. 106 (B7), 13,443-13,454.

Bystricky, M., Kunze, K., Burlini, L., Burg, J.-P., 2000. High shear strain of olivine aggregates: rheological and seismic consequences. Nature 290, 1564-1567.

Cameron, M., Papike, J.J., 1981. Structural and chemical variations in pyroxenes. Am. Miner. 66, 1-50.

Carrez, P., Ferré, D., Denoual, C., Cordier, P., 2010. Modelling thermal activation of $<110>\left\{\begin{array}{lll}1 & 1 & 0\end{array}\right\}$ slip at low temperature in SrTiO3. Scr. Mater. 63, 434-437.

Carrez, Ph., Walker, A.M., Metsue, A., Cordier, P., 2008. Evidence from numerical modelling for 3D spreading of [ [ $\left.\begin{array}{lll}0 & 0 & 1\end{array}\right]$ screw dislocations in Mg2SiO4 forsterite. Philos. Mag. 88 (16), 2477-2485.

Couvy, H., Frost, D.J., Heidelbach, F., Nyilas, K., Ungar, T., Mackwell, S., Cordier, P., 2004. Shear deformation experiments of forsterite at $11 \mathrm{GPa}-1400{ }^{\circ} \mathrm{C}$ in the multianvil apparatus. Eur. J. Miner. 16, 877-889.
Castelnau, O., Blackman, D.K., Lebensohn, R.A., Ponte Castañeda, P., 2008 Micromechanical modelling of the viscoplastic behavior of olivine. J. Geophys. Res. 113, B09202. http://dx.doi.org/10.1029/2007JB005444.

Castelnau, O., Lebensohn, R.A., Ponte Castañeda, P., Blackman, D.K., 2008b. Earth mantle rheology inferred from homogenization theories, in: O. Cazacu (Ed.) Multi-Scale Modeling of Heterogeneous Materials, Wiley, ISBN 9781848210479.

Castelnau, O., Blackman, D.K., Becker, T.W., 2009. Numerical simulations of texture development and associated rheological anisotropy in regions of complex mantle flow. Geophys. Res. Lett. 36, L12304.

Castelnau, O., Cordier, P., Lebensohn, R.A., Merkel, S., Raterron, P., 2010. Microstructures and rheology of the earth's upper mantle inferred from a multiscale approach. C.R. Phys. 11, 304-315.

De Bresser, J.H.P., Peach, C.J., Reijs, J.P.J., Spiers, C.J., 1998. On dynamic recrystallisation during solid state flow: effects of stress and temperature. Geophys. Res. Lett. 25, 3457-3460.

De Bresser, J.H.P., Ter Heege, J.H., Spiers, C.J., 2001. Grain size reduction by dynamic recrystallization: can it result in major rehological weakening? Int. J. Earth Sci. 90, 28-45.

Demouchy, S., Schneider, S.E., Mackwell, S.J., Zimmerman, M.E., Kohlstedt, D.L., 2009. Experimental deformation of olivine single crystals at lithospheric temperatures. Geophys. Res. Lett. 36, L04304. http://dx.doi.org/10.1029/ 2008 GL036611.

Detrez, F., Castelnau, O., Cordier, P., Merkel, S., Raterron, P., in preparation. Secondorder theory for the effective behavior in viscoplatic polycrystals without sufficient slip system families: application to olivine.

Durham, W.B., Goetze, C., 1977. Plastic flow of oriented single crystals of olivine, 1 mechanical data. J. Geophys. Res. 82 (36), 5737-5753.

Durham, W.B., Mei, S., Kholstedt, D.L., Wang, L., Dixon, N.A., 2009. New measurement of activation volume in olivine under anhydrous conditions. Phys. Earth Planet. Int. 172, 67-73.

Dohmen, R., Chakraborty, S., Becker, H.-W., 2002. Si and O diffusion in olivine and implications for characterizing, plastic flow in the mantle. J. Geophys. Res. 29 (21), 2030. http://dx.doi.org/10.1029/2002GL015480.

Doukhan, N., Doukhan, J.C., Ingrin, J., Jaoul, O., Raterron, P., 1993. Early partial melting in pyroxenes. Am. Mineral. 78, 1246-1256.

Durinck, J., Carrez, P., Cordier, P., 2007. Application of the Peierls-Nabarro model to dislocations in forsterite. Eur. J. Miner. 19, 631-639.

Eshelby, J.D., 1957. The determination of the elastic field of an ellipsoidal inclusion, and related problems. Proc. R. Soc. London, A 241, 376-396.

Ferré, D., Carrez, P., Cordier, P., 2008. Modeling dislocation cores in SrTiO3 using the Peierls-Nabarro model. Phys. Rev. B 77, 014106.

Ford, J., Wheeler, J., Movchan, A.B., 2002. Computer simulation of grain boundary creep. Acta Mater. 50, 3941-3955.

Frost, D.J., 2008. The upper mantle and transition zone. Elements 4, 171-176. http:// dx.doi.org/10.2113/gselements.4.3.171.

Frost, B.R., 1991. Introduction to oxygen fugacity and its petrologic importance. In: Lindsley, D.H. (Ed.), Reviews in Mineralogy. Oxide Minerals: Petrologic and Magnetic Significance, vol. 25. Mineralogical Society of America, New York, pp. 1-10.

Frost, D.J., McCammon, C.A., 2008. The redox state of Earth's mantle. Annu. Rev. Earth Planet. Sci. 36, 389-420.

Gasperimi, P., Dal Forno, G., Boschli, E., 2004. Linear or non-linear rheology in the Earth's mantle: the prevalence of power-law creep in the postglacial isostatic readjustment of Laurentia. Geophys. J. Int. 157, 1297-1302.

Gilormini, P., 1996. A critical evaluation for various nonlinear extensions of the selfconsistent model. In: A. Pineau, A. Zaoui (Eds.), Proceedings of the IUTAM Symposium on Micromechanics of Plasticity and Damage of Multiphase Materials, Sèvres, France, 1995, Kluwer Academic Publishers, Dordrecht, pp. 67-74.

Girard, J., Chen, J., Raterron, P., Holyoke, C.W.I.I.I., 2013. Hydrolytic weakening of olivine at mantle pressure: evidence of [100](010) slip system softening from single crystal deformation experiments. Phys. Earth Planet. Int. 216, 12-20.

Godard, G., Van Roermund, L., 1995. Deformation-induced clinopyroxenes fabrics in eclogite. J. Struct. Geol. 17 (10), 1425-1443.

Gómez Barreiro, J., Lonardelli, I., Wenk, H.R., Dresen, G., Rybacki, E., Ren, Y., Tomé C.N., 2007. Preferred orientation of anorthite deformed experimentally in Newtonian creep. Earth Planet. Sci. Lett. 264, 188-207.

Gung, Y., Panning, M., Romanowicz, B., 2003. Global anisotropy and the thickness of continents. Nature 422, 707-711.

Hansen, L.N., Zimmerman, M.E., Kohlstedt, D.L., 2011. Grain boundary sliding in San Carlos olivine: flow law parameters and crystallographic-preferred orientation. J. Geophys. Res. 116, B08201. http://dx.doi.org/10.1029/2011JB008220.

Hansen, L.N., Zimmerman, M.E., Kohlstedt, D.L., 2012. The influence of microstructure on the deformation of olivine in the grain-boundary sliding regime. J. Geophys. Res. 117 (B9). http://dx.doi.org/10.1029/2012JB009305.

Hansen, L.N., Zimmerman, M.E., Kohlstedt, D.L., 2013. Laboratory measurements of viscous anisotropy of olivine aggregates. Nature 492, 415-418.

Hirth, G., Kohlstedt, D.L., 2003. Rheology of the upper mantle and the mantle wedge: a view from the experimentalists, in: Inside the Subduction Factory, Geophys. Monogr. Ser. 138, J. Eiler (Ed.), AGU, Washington, D. C., 83-105.

Hutchinson, J.W., 1977. Creep and plasticity of hexagonal polycrystals as related to single crystal slip. Met. Trans. 8A (9), 1465-1469.

Ingrin, J., Doukhan, N., Doukhan, J., 1991. High-temperature deformation of diopside single crystal, 2, transmission electron microscopy investigation of the defect microstructures. J. Geophys. Res. 96 (B9), 14287-14297. 
Ingrin, J., Doukhan, N., Doukhan, J.C., 1992. Dislocation glide systems in diopside single crystals deformed at 800-900 ${ }^{\circ} \mathrm{C}$. Eur. J. Miner. 4, 1291-1302.

Jaoul, O., Raterron, P., 1994. High-temperature deformation of diopside crystal, 3, Influence of pO2 and SiO2 precipitation. J. Geophys. Res. 99 (B5), 9423-9439.

Jung, H., Mo, W., Green, H.W., 2009. Upper mantle seismic anisotropy resulting from pressure-induced slip transition in olivine. Nat. Geosci. 2, 73-77.

Ji, S., Wang, Z., Wirth, R., 2001. Bulk flow strength of forsterite-enstatite composites as a function of forsterite content. Tectonophysics 341, 69-93.

Kaminski, E., Ribe, N.M., Broadwaeys, J.T., 2004. D-Rex, a program for calculation of seismic anisotropy due to crystal lattice preferred orientation in the convective upper mantle. Geophys. J. Int. 158, 744-752.

Karato, S.I., 1992. On the Lehmann discontinuity. Geophys. Res. Lett. 19 (22), 2255 2258.

Kohlstedt, D.L., Goetze, C., 1974. Low-stress high-temperature creep in olivine single crystals. J. Geophys. Res. 79 (14), 2045-2051.

Kollé, J.J., Blacic, J.D., 1982. Deformation of single-crystal clinopyroxenes, 1, mechanical twinning in diopside and hedenbergite. J. Geophys. Res. 87, 40194034.

Kollé, J.J. Blacic, J.D. 1983. Deformation of single-crystal clinopyroxenes, 2 dislocation-controlled flow processes in hedenbergite. J. Geophys. Res. 88, 2381-2393.

Kröner, E., 1978. Self-consistent scheme and graded disorder in polycrystal elasticity. J. Phys. F: Metal Phys. 8, 2261-2267.

Lebensohn, R.A., Castelnau, O., Brenner, R., Gilormini, P., 2005. Study of the antiplane deformation of linear 2-D polycrystals with different microstructure. Int. J. Solids Struct. 42, 5441-5459.

Lebensohn, R.A., Tomé, C.N., Ponte Castañeda, P., 2007. Self-consistent modeling of the mechanical behavior of viscoplastic polycrystals incorporating field fluctuations. Philos. Mag. 87 (28), 4287-4322.

Lebensohn, R.A., Hartley, C.S., Tomé, C.N., Castelnau, O., 2010. Modelling the mechanical response of polycrystals deforming by climb and glide. Philos. Mag. 90 (5), 567-583.

Liebermann, Multi-anvil., 2011. High pressure apparatus: a half-century of development and progress. High Pressure Res. http://dx.doi.org/10.1080/ 08957959.2011.618698.

Mackwell, S.J., Kohlstedt, D.L., Paterson, M.S., 1985. The role of water in the deformation of olivine single crystals. J. Geophys. Res. 90, 11319-11333.

Mainprice, D., Barruol, G., Ben Ismaïl, W., 2000. The seismic anisotropy of Earth's mantle: From single crystal to polycrystal. In: "Earth's deep interior: mineral physics and tomography from the atomic scale to global scale", S.I. Karato, A Forte, R.C. Liebermann, G. Masters and L. Stixrude (Eds.), Geophysical Monograph 117, American Geophysical Union, Washington D.C., 237-264.

Mainprice, D., Tommasi, A., Couvy, H., Cordier, P., Frost, D.J., 2005. Pressure sensitivity of olivine slip systems and seismic anisotropy of Earth's upper mantle. Nature 433, 731-733.

Mercier, J.C., Anderson, D.A., Carter, N.L., 1977. Stress in the lithosphere: inferences from steady state flow of rocks. Pure Appl. Geophys. 115, 117-138.

Metsue, A., Carrez, P., Denoual, C., Mainprice, D., Cordier, P., 2010. Peierls-Nabarro modelling of dislocation in diopside. Phys. Chem. Miner. 37, 711-720.

Milton, G.W., 1985. The coherent potential approximation is a realizable effective medium scheme. Commun. Math. Phys. 99, 483-503.

Miyazaki, T., Sueyoshi, K., Hiraga, T., 2013. Olivine crystals align during diffusion creep of Earth's upper mantle. Nature 502, 321-326.

Ohuchi, T., Kawazoe, T., Nishihara, Y., Nishiyama, N., Irifune, T., 2011. High pressure and temperature slip transitions in olivine and variations in upper mantle anisotropy. Earth Planet. Sci. Lett. 304, 55-63.

Ohuchi, T., Irifune, T., 2013. Develoment of A-type olivine fabric in water-rich deep upper mantle. Earth Planet. Sci. Lett. 362, 20-30.

Phakey, P., Dollinger, G., Christie, J., 1972. Transmission electron microscopy of experimentally deformed olivine crystals. In: H.C. Heard et al. (Eds.), Flow and Fracture of Rocks, Geophys. Monogr. Ser., vol. 16, pp. 117-138, AGU, Washington, D. C. doi: 10.1029/GM016p0117.

Poirier, J.P., 1985. Creep of crystals, high-temperature deformation processes in metals, ceramics and minerals. Cambridge Earth Science Series, Cambridge University Press, New York, Chapter 4, pp. 94-144.
Ponte Castañeda, P., 2002. Second-order homogenization estimates for nonlinear composites incorporating field fluctuations. I - Theory. J. Mech. Phys. Solids 50, 737-757.

Poumellec, B., Jaoul, O., 1984. Influence of PO2 and PH2O on the high temperature plasticity of olivine. In: R.F. Tressler, R.C. Bradt (Eds.), Deformation of Ceramic Il Deformation of Ceramic Il, BIen. bubl. Corp., pp. 281-305.

Raterron, P., Jaoul, O., 1991. High-temperature deformation of diopside single crystal 1: mechanical data. J. Geophys. Res. 96 (B9), 14,277-14,286.

Raterron, P., Doukhan, N., Jaoul, O., Doukhan, J.C., 1994. High temperature deformation of diopside, IV: predominance of 110 glide above $1000{ }^{\circ} \mathrm{C}$. Phys. Earth Planet. Int. 82, 209-222.

Raterron, P., Ingrin, J., Jaoul, O., Doukhan, N., Elie, F., 1995. Early partial melting of diopside under high pressure. Phys. Earth Planet. Int. 89, 77-88.

Raterron, P., Chen, J., Li, L., Weidner, D., Cordier, P., 2007. Pressure-induced slipsystem transition in forsterite: single-crystal rheological properties at mantle pressure and temperature. Am. Miner. 92, 1436-1445.

Raterron, P., Merkel, S., 2009. In situ rheological measurements at extreme pressure and temperature using synchrotron X-ray diffraction and radiography. J. Synchrotron Rad. 16, 748-756.

Raterron, P., Amiguet, E., Chen, J., Li, L., Cordier, P., 2009. Experimental deformation of olivine single crystals at mantle pressure and temperature. Phys. Earth Planet. Int. 172, 74-83.

Raterron, P., Chen, J., Geenen, T., Girard, J., 2011. Pressure effect on forsterite dislocation slip systems: implications for upper-mantle LPO and low viscosity zone. Phys. Earth Planet. Int. 188, 26-36.

Raterron, P., Girard, J., Chen, J., 2012. Activities of olivine slip systems in the upper mantle. Phys. Earth Planet. Int. 200-201, 105-112.

Ricoult, D.L., Kohlstedt, D.L., 1985. Experimental Evidence for the effect of chemical environment upon the creep rate of olivine. In: Schock, R.N. (Ed.), Point Defects in Minerals, Geophysical Monograph Series, 31. American Geophysical Union, Washington, DC, pp. 171-184.

Ross, C.R., Ave'Lallemant, H.G., Carter, N.L., 1980. Stress dependence of recrystallized-grain and subgrain size in olivine. Tectonophysics 70, 39-61.

Sachs, G., 1928. Zur ableitung einer Fliessbedingung. Z. Ver. Dtsch. Ing. 72, 734-736.

Sundberg, M., Cooper, R.F., 2008. Crystallographic preferred orientation produced by diffusional creep of harzburgite: effects of chemical interactions among phases during plastic flow. J. Geophys. Res. 113 (B12). http://dx.doi.org/ 10.1029/2008JB005618.

Tielke, J.A., Zimmerman, M.E., Dillman, A.M., Kohlstedt, D.L., 2012. Direct shear of olivine single crystals under anhydrous conditions: implications for lattice preferred orientation and seismic anisotropy in the lithospheric mantle. American Geophysical Union, Fall Meeting.

Tommasi, A., Tikoff, B., Vauchez, A., 1999. Upper mantle tectonics: threedimensional deformation, olivine crystallographic fabrics and seismic properties. Earth Planet. Sci. Lett. 168, 173-186.

Tommasi, A., Mainprice, D., Canova, G., Chastel, Y., 2000. Viscoplastic self-consistent and equilibrium-based modelling of olivine lattice preferred orientations. 1. Implications for the upper mantle seismic anisotropy. J. Geophys. Res. 105, 7893-7908.

Turcotte, D.L., Schubert, G., 2002. Geodynamics, Second ed. Cambridge University Press, New York, pp. 456.

Walker, A.M., 2012. The effect of pressure on the elastic properties and seismic anisotropy of diopside and jadeite from atomic scale simulation. Phys. Earth Planet. Int. 192-193, 81-89.

Wenk, H.R., Tomé, C.N., 1999. Modelling dynamic recrystallization of olivine aggregates deformed in simple shear. J. Geophys. Res. 104, 25,513-25,527.

Wheeler, J., 1992. The importance of pressure solution and Coble creep in the deformation of polymineralic rocks. J. Geophys. Res. 97, 4579-4586.

Wheeler, J., 2009. The preservation of seismic anisotropy in the Earth's mantle during diffusion creep. Geophys. J. Int. 178, 1723-1732.

Wheeler, J., 2010. Anisotropic rheology during grain boundary diffusion creep and its relation to grain rotation, grain boundary sliding and superplasticity. Philos. Mag. 90, 2841-2864.

Willis, J.R., 1981. Variational and related methods for the overall properties of composites. Adv. Appl. Mech. 21, 2-78. 